\title{
Working
}

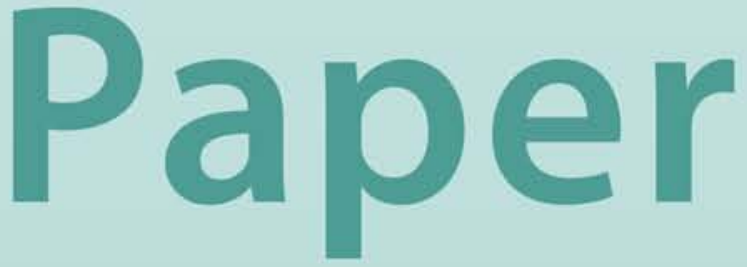




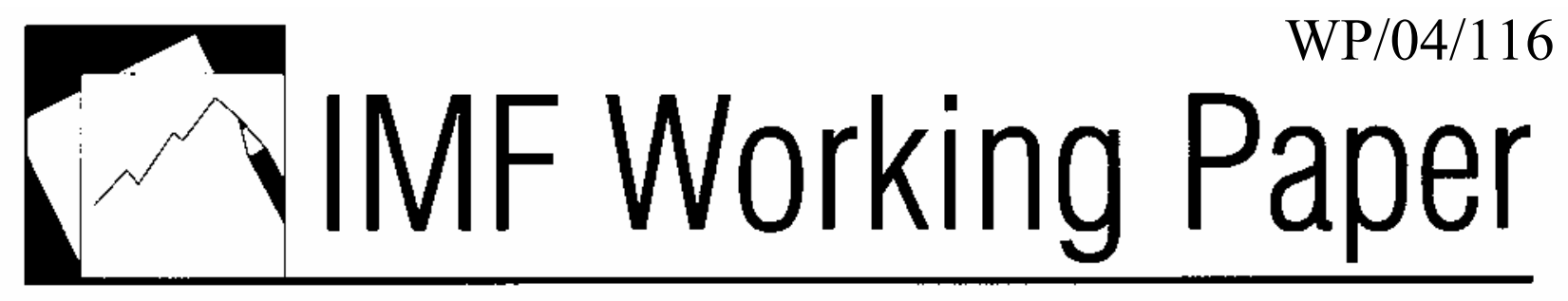

\author{
Assessing the Assessment: \\ A Critical Look at the June 2003 \\ Assessment of the United Kingdom's \\ Five Tests for Euro Entry \\ Carlo Cottarelli and Julio Escolano
}




\title{
IMF Working Paper
}

European Department

\section{Assessing the Assessment: A Critical Look at the June 2003 Assessment of the United Kingdom's Five Tests for Euro Entry}

\author{
Prepared by Carlo Cottarelli and Julio Escolano ${ }^{1}$
}

July 2004

\begin{abstract}
This Working Paper should not be reported as representing the views of the IMF. The views expressed in this Working Paper are those of the author(s) and do not necessarily represent those of the IMF or IMF policy. Working Papers describe research in progress by the author(s) and are published to elicit comments and to further debate.

This paper provides a framework for evaluating the decision to enter a currency area, including the best timing for entry, and uses it to evaluate the assessment of the five tests for euro entry published by the U.K. Treasury in June 2003. The breadth and depth of its assessment is impressive by any standard. Nonetheless, this paper points at some areas that deserve to be explored further in future assessments. Covering these areas would not necessarily have changed the assessment's conclusion, namely that the case for entry is not yet "clear and unambiguous," but it would have strengthened any conclusion reached. In addition, the paper highlights that in several areas relevant to the entry decision, the margin for uncertainty will remain significant, regardless of any reasonable attempt to reduce it.
\end{abstract}

JEL Classification Numbers: E00, E42

Keywords: Assessing the Assessment, Five Tests, Euro Entry

Author’s E-Mail Address: ccottarelli@imf.org and jescolano@imf.org

\footnotetext{
${ }^{1}$ Carlo Cottarelli is Deputy Director in the IMF's European Department; Julio Escolano is Deputy Division Chief in the same department. Petya Koeva prepared Appendix I. We would like to thank her and the participants in a seminar held at the U.K. Treasury for extremely useful comments on an earlier draft of this paper.
} 
Contents

I. Introduction

II. An Analytical Framework.

A. Euro Entry as an Investment Decision: Full Convergence (Or Flexibility) and no

Uncertaint y.....

B. Imperfect Convergence (or Imperfect Flexibility) .............................................

C. Uncertainty and the Value of Waiting ..........................................................

III. The Five Tests and the Twelve Issues ............................................................... 10

A. Issue 1: How Should the Entry Decision Problem be Formulated?........................ $\frac{10}{12}$

B. Issue 2: What is the Return from Entry Under full Convergence or Flexibility? ... 12

C. Issue 3: What is the Cost of Delaying Entry Arising from the Time Discount

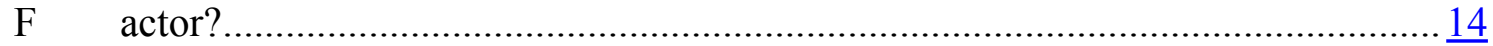

D. Issue 4: How Does the Shape of the Return Curve Change over Time? ................ 17

E. Issue 5: How Convergent Is the U.K. Economy With Respect To the Euro-Area Average, in Terms of Both Idiosyncratic Shocks and Idiosyncratic Transmission

Mechanism?

F. $\quad$ Issue 6: How Flexible Is the U.K. Economy and, Relatedly, How Much Flexibility Is Needed to Compensate for Imperfect Convergence? .................................... 19

G. Issue 7: What Is the Effect of Output Volatility on Average Output Growth?....... $\underline{23}$

H. Issue 8: What Is the Welfare Cost of Increased Output Volatility?...................... 24

I. Issue 9: How Fast Is Endogenous Convergence? ............................................ 24

J. Issue 10: How Much Can Be Gained In Terms Of Improved Convergence and Increased Flexibility as a Result of Waiting (as Reforms are Implemented)? ....... 26

K. Issue 11: Is the case for No Entry Made Stronger by Current Idiosyncratic

Shocks $\quad$ ? ............................................................................................. 26

L. Issue 12: What Weight Should Be Given to the Value of More Information that Can Be Gathered with the Passage of Time?....

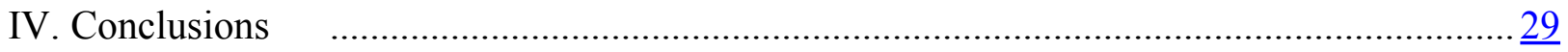

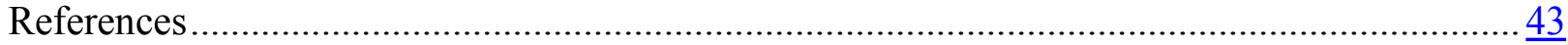

Appendixes

I. The Option Value of Delaying EMU Entry ......................................................... $\underline{36}$

II. Domestic and Foreign Direct Investment (FDI) ................................................ 39 
Boxes

1. Effects of European Economic and Monetary Union (EMU) on Trade and Growth ....... 15

2. Consumption and the Housing Market ............................................................ 20

3. Quantifying the Welfare Cost of Output Volatility ............................................. 25

4. Is the United Kingdom Currently Affected by an Idiosyncratic Shock? ...................... 28

Figures

1. The Relative Return Curve ............................................................................. 11

2. Private Consumption Contribution to GDP Growth ...............................................

3. Relative Contribution of Private Consumption to GDP Growth ................................ $\underline{32}$

4. Real House Prices and Consumption per Capita .................................................... $\underline{33}$

5. Correlation Coefficients Between Private Consumption Growth and House Price

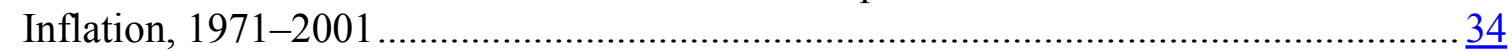

6. Real House Prices .....................................................................................

Appendix Figures

A1. France, Germany, and the United Kingdom: Ten-Year Benchmark Government Bond Yields

Tables

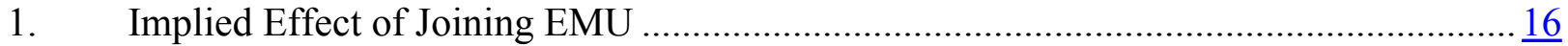

2. Selected Housing Market Features ..................................................................

Appendix Tables

A1. Inward Foreign Direct Investment (FDI) Flows, by Origin ................................. 40

A2. FDI Inflows into European Union (EU) "Out”" Countries .......................................... 41

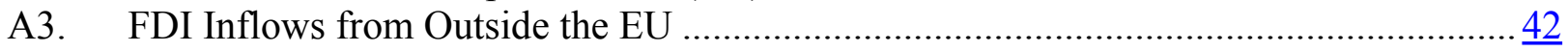




\section{INTRODUCTION}

The U.K. Government's policy on European Economic and Monetary Union (EMU) membership was set by Chancellor Gordon Brown in his October 1997 statement to parliament, which included a commitment to the principle of joining EMU. ${ }^{2}$ A key element of this policy is that at the time the actual decision to join is taken by the government, the economic case for euro adoption must be "clear and unambiguous," as further specified by five economic tests. These tests relate to five questions that are here reproduced verbatim (with the term each test is commonly referred to indicated in parenthesis):

(1) Are business cycles and economic structures compatible so that we and others could live comfortably with euro interest rates on a permanent basis? (convergence test)

(2) If problems emerge is there sufficient flexibility to deal with them? (flexibility test)

(3) Would joining EMU create better conditions for firms making long-term decisions to invest in Britain? (investment test)

(4) What impact would entry into EMU have on the competitive position of the United Kingdom's financial services industry, particularly the City's wholesale markets? (financial services test)

(5) In summary, will joining EMU promote higher growth, stability and a lasting increase in jobs? (growth, stability, and employment test)

In 1997, the government concluded that based on these tests, the case for entry was not yet clear and unambiguous and decided to reassess it after the following elections, which took place in 2001. In June 2003, the U.K. Treasury issued a new assessment (thereafter referred to as the Assessment), ${ }^{3}$ together with 18 related studies covering a comprehensive range of issues, ${ }^{4}$ and concluded that the case for entry was not yet clear and unambiguous:

\footnotetext{
${ }^{2}$ Chancellor Brown (1997), and H.M. Treasury (1997).

${ }^{3}$ H.M. Treasury (2003a). The character $\uparrow$ will henceforth indicate paragraphs in the Assessment.
}

${ }^{4}$ HM Treasury (2003b). The impressive range of topics covered by the studies is indicated by their titles: "The five tests framework; Analysis of European and UK business cycles and shocks"; "Estimates of equilibrium exchange rates for sterling against the euro"; "Housing, consumption and EMU"; "EMU and the monetary transmission mechanism"; "Modelling the transition to EMU"; "Modelling shocks and adjustment mechanisms in EMU"; "EMU and labour market flexibility"; "The exchange rate and macroeconomic adjustment"; "EMU and the cost of capital"; "EMU and business sectors"; "The location of financial activity and the euro"; "EMU and trade"; "Prices and EMU"; "The United States as a monetary union"; "Policy frameworks in the UK and EMU"; "Submissions on EMU from leading academics; "Fiscal stabilisation and EMU—a discussion paper". These studies, prepared by academics, 
- The convergence test was not yet deemed to have been met. Although there had been substantial convergence since 1997, remaining differences in cyclical dynamics and economic structures between the United Kingdom and the euro area still posed significant risks to stability. Specifically, the Assessment underscored the risks stemming from differences in housing markets, which made U.K. consumption more sensitive to interest rates and more volatile as a consequence of house-price cycles.

- The flexibility test was not met either. Although there had also been progress on this front, there was insufficient assurance that, in the absence of monetary independence, the economy could withstand idiosyncratic shocks without risking unacceptable welfare losses.

- The financial sector test was met, as entry was expected to enhance further the already strong competitive position of the City in the wholesale financial services business.

- The conclusion on the remaining two tests was that they would be met - and, hence, investment, growth, and employment would benefit from entry-once sustainable and durable convergence had been achieved. But since the convergence test was regarded as not having been met, the third and fifth tests were also regarded as not having been met.

The Assessment also includes several reform initiatives and proposals aiming to foster convergence and flexibility. These initiatives are also regarded as good for economic performance independently of the EMU decision. More specifically;

- as of December 2003, the inflation target of the Monetary Policy Committee has been defined in terms of the harmonized index used in the euro area (HICP, renamed CPI), rather than in terms of the traditional U.K. retail price index (RPIX);

- the government launched a program of consultations in areas related to the housing market with a view to dampening house price and consumption volatility;

- the Assessment reiterates the government's commitment to promote flexibility in labor, product, and financial markets, and summarizes several ongoing initiatives in these areas; and

- the government opened a discussion on possible reforms of the United Kingdom's fiscal framework after joining EMU to reinforce the stabilization role of fiscal policy, including strengthening automatic stabilizers and introducing rules for countercyclical fiscal action.

Against this background, this paper does not aim at evaluating whether the final conclusion of the Assessment - that the moment for entry had not yet come-was "right" or "wrong," but, rather, at discussing the rationale for this choice and whether all relevant economic aspects of the issue received sufficient attention. The quality and breadth of the analysis carried out by the U.K. Treasury was unprecedented for an economic decision of this sortthe assessment deals with most of the issues relevant for assessing the case for euro entry

researchers, and treasury staff, survey the growing academic literature on these topics and constitute in their own right a valuable addition to this literature. 
thoroughly and its conclusions are typically backed up by state-of-the-art economic reasoning and empirical evidence. But improvements are possible and could usefully be taken into account when the tests are reassessed. In particular, this paper argues that it would be important to (i) clarify the overall analytical framework from which the five tests are derived so as to highlight their specific role with respect not only to the decision of whether to enter but also of when to enter; (ii) explore more explicitly and thoroughly some important issues; and (iii) highlight more clearly the several areas where the Assessment involves a high degree of economic judgment, rather than economic measurement, so as to at least acknowledge that margins of uncertainty will inevitably remain. Exploring these issues along the lines proposed in this paper might not have necessarily changed the Treasury's overall assessment, but it would have strengthened any conclusion reached.

The paper is structured as follows. Section II presents a simple analytical framework to highlight 12 key issues that are relevant to evaluate the entry decision. Section III discusses to what extent the Assessment addresses these issues. Sections IV summarizes the conclusions.

\section{An AnALYTiCAL FrameWORK}

The five tests span such a broad range of economic issues that they can hardly be regarded as incomplete. Growth, employment, trade, economic stability and flexibility, investment, financial sector services are all covered. In this sense one has to conclude that the five tests are broadly appropriate to evaluate the economic case for entry. ${ }^{5}$ However, the assessment could have benefited from a clarification of the analytical framework from which the five tests are derived, particularly with respect to the issue of the appropriate timing of entry. Granted, the tests can be generally linked to the optimal currency area literature, pioneered by Mundell (1961): entering a currency area may boost trade, investment and growth through a number of channels (this seems to be the focus of the last three tests), ${ }^{6}$ but this has to be weighed against the increased output volatility that may arise from the loss of monetary independence, unless the economy is sufficiently similar to those of the common currency area (the first test) or the economy is sufficiently flexible, so that the lack of monetary flexibility does not matter much (the second test). ${ }^{7}$ However, assessing not only whether but also when it is appropriate to enter a monetary area requires a more complex analytical framework. This section aims to provide such a framework and to identify 12 issues that are critical to assess the entry decision.

\footnotetext{
${ }^{5}$ See IMF (2000) and IMF Country Report 03/48, February 5, 2003 (paragraph 37, in particular).

${ }^{6}$ Note, however, that the last test is presented as a summary tests ("In summary, ..."), which makes it difficult to see it as a separate test.

${ }^{7}$ See $\llbracket 18-44$ in the introduction to the Assessment.
} 


\section{A. Euro Entry as an Investment Decision: Full Convergence (Or Flexibility) and no Uncertainty}

The decision on whether and when a country (hereinafter "the United Kingdom") should enter a currency area (hereinafter the "euro area") can be assessed as if it were an investment decision, that is, by looking at the net present value (NPV) of the entry decision ("the investment") at the time the assessment is made ("today"). The United Kingdom can decide to enter today or not to enter today. If it decides not to enter today it may be because entry is never going to be appropriate or because entry at a later date may be more appropriate. ${ }^{8}$ An entry assessment made today should then focus on establishing the moment when today's NPV from entry is maximized. All this does not take into account the existence of uncertainty, and whether the latter can be reduced by waiting, and the asymmetry in the decision set (the decision not to enter is reversible, while that of entering is irreversible). We will discuss these complications later. Let us assume for the moment the absence of uncertainty. Let us also assume that the United Kingdom has already "fully converged."

More specifically, assume that: (i) the economic shocks hitting the U.K. economy are fully correlated with the shocks hitting the euro area; and (ii) the transmission mechanism of monetary policy in the United Kingdom is equal to the average of the euro area. This means that the monetary policy setting in the euro area will be optimal for the United Kingdom. Alternatively, assume that the U.K. economy is fully flexible (in the sense that the setting of nominal monetary policy instruments becomes entirely irrelevant).

In this case, the return from entering the euro area may be described by the curve $f_{\tau}(t)$ in the upper panel of Figure 1 (the "relative return curve"), which expresses the relative deviation of output in case of entry from its "baseline" in the absence of entry. The curve is always positive starting from the entry date $\tau$, as euro-entry, at least under full convergence and flexibility, is expected to raise output, albeit gradually, through a number of channels: increased trade, higher investment and FDI, reduced transaction costs, reduced exchange rate variability, being the most important ones. The area under the curve is directly related to the net present value (NPV) of entering the euro area.

From an economic perspective, the right question to ask is what is the value of $\tau$ (the entry date) that maximizes the NPV at time 0 of the total return curve $F_{\tau}(t)=(1+g)^{t} f_{\tau}(t)$, or:

$$
\max _{\tau} \mathrm{NPV}_{0}^{\tau}=\sum_{t=0}^{\infty} \frac{(1+\mathrm{g})^{t} f_{\tau}(t)}{(1+r)^{t}}
$$

Where $g$ is the growth rate of output in the case of not entering EMU (assumed to be constant over time for simplicity), and $\mathrm{r}$ is the time discount rate. If the curve $f_{\tau}(t)$ is always positive, the entry decision has clearly a positive return. In this case, and if the curve is time invariant,

\footnotetext{
${ }^{8}$ This disregards, for simplicity, the inevitable lags between the entry decision and the actual entry. The duration of this lag is difficult to assess, as it does not depend only on the political process in the United Kingdom (including a referendum), but also on euro-areas procedures.
} 
there is a clear case for entering today because of the time discount factor: delaying entry would simply postpone reaping the benefit from entry. ${ }^{9}$

However, the shape under the curve $f_{\tau}(t)$ may be time dependent, and this is the general case described in (1), where the relative return curve $f_{\tau}(t)$ is marked by a subscript $\tau$ (the entry date). Even if the difference affects only the return in the early years and not the long-term gains, the magnitude of the area under the curve will be affected and, hence, its NPV. In this case $\mathrm{NPV}_{0}^{\tau}$ could be higher than $\mathrm{NPV}_{0}^{0}$ for $\tau>0$, and postponing entry would be appropriate.

This discussion highlights a first set of issues relevant for assessing the case for entry:

Issue 1: How should the entry decision problem be formulated?

Issue 2: What is the return from entry (i.e., the shape of the return curve) under full convergence or flexibility?

Issue 3: What is the cost of delaying entry arising from the time discount factor?

Issue 4: How is the return curve affected by the passage of time?

\section{B. Imperfect Convergence (or Imperfect Flexibility)}

The absence of full convergence implies that the monetary policy response to shocks may be inadequate to the needs of the U.K. economy. This may happen because the United Kingdom is subject to idiosyncratic shocks or because the U.K. transmission mechanism of monetary policy is different from the average of the euro area. These problems are bound to become less severe over time, reflecting endogenous convergence (i.e., the fact that the United Kingdom would become more similar to the euro area after EMU entry), but may initially be significant. This has three implications for the shape of the return curve:

- The return curve would be more volatile than in the upper panel of Figure $1 .{ }^{10}$

- Average growth may also be lower if one believes that stability is important for growth.

- Entry costs would be larger if entry occurs at a time when the United Kingdom is being hit by a strong idiosyncratic shock, as these costs will be felt immediately. Cases in point may be entry in the presence of a housing market boom or when the exchange rate is far away from long-term equilibrium. To the extent that large shocks are unlikely to recur, as they will in case of endogenous convergence, there could then be a case for waiting.

The importance of these factors is higher if the economy is not flexible enough. At least in principle, a fully flexible economy would be able to adjust to demand shocks, eliminating

\footnotetext{
${ }^{9}$ This assumes that the time discount rate $r$ is higher than the economy's growth rate $g$.

${ }^{10}$ This assumes that monetary policy in the United Kingdom is adequately managed. Of course, an independent monetary policy does not help if it is mismanaged, in which case a country can always benefit from entry.
} 
any impact on output. ${ }^{11}$ While in practice this is unlikely to be the case, it is reasonable to argue that a more flexible economy can withstand more easily shocks that are not offset by monetary policy action.

The full line in the lower panel of Figure 1 illustrates how the return curve could change if convergence were imperfect (or not fully offset by sufficient flexibility). Volatility is expected to decline over time, reflecting endogenous convergence. ${ }^{12}$ Note also that the average level of the curve could be lower than under full convergence if one assumes that high output volatility discourages growth.

But this is not the whole story, as, in assessing the cost of increased volatility, one has to take into account the dislike of output volatility per se. Thus, a fair comparison with the case depicted in the upper panel of Figure 1 would require transforming the solid line curve in the lower panel into a curve that were welfare equivalent. This is the dotted curve in the lower panel, which is on average lower than the volatile curve, to reflect the welfare costs of output volatility. Note that now a sizable part of the curve is in negative territory, indicating a lower output level than in the no-entry case. With a sufficiently large intertemporal rate of discount, the NPV could then turn negative, in principle.

In sum, in the presence of imperfect convergence or insufficient flexibility, a second set of issues needs to be addressed:

Issue 5: How convergent is the U.K. economy with respect to the euro-area average, in terms of both idiosyncratic shocks and idiosyncratic transmission mechanism?

Issue 6: How flexible is the U.K. economy and, relatedly, how much flexibility in needed to compensate for imperfect convergence?

Issue 7: What is the effect of output volatility on average output growth?

Issue 8: What is the welfare cost of increased output volatility?

Issue 9: How fast is endogenous convergence?

Issue 10: How much can be gained in terms of improved convergence and increased flexibility as a result of waiting (as reforms are implemented)?

Issue 11: Is the case for no entry made stronger by current particular idiosyncratic shocks?

\footnotetext{
${ }^{11}$ However, as discussed in the Assessment ( $₫$ 2.31, in particular), more price and wage flexibility, while reducing output volatility, would increase inflation volatility.

12 The return curve illustrates the volatility of output with respect to a baseline where output volatility is expected to be minimized reflecting the use of an independent monetary policy. In principle, one should assess whether the increased volatility arising from the entry decision should really be added to the residual volatility of the baseline, or whether it could possibly offset it.
} 


\section{Uncertainty and the Value of Waiting}

Economic decisions typically take place in an uncertain environment reflecting not only random shocks, but also insufficient information. The passage of time allows gathering more information and gauging trends better. This factor becomes particularly important in deciding whether to enter EMU for two reasons. First, the decision to enter EMU is not easily reversible, while the decision not to enter is reversible: the United Kingdom is not faced with a now-or-never proposition, but if it decides to enter there is no turning back. Once the decision to enter is taken, additional information becomes useless. However, if the decision is made to defer entry, additional information can still be used to decide on a later entry.

Second, additional information is particularly important in the decision to enter the euro-area because the latter is new, and little is yet know about its actual structural implications for the economies of member states. More information will become available over the coming years on the working of euro area institutions, the effect on trade, growth, and investment not of a generic monetary union, but of the euro-area, the speed of endogenous convergence, and so on. In more technical terms, the shape of the return curve in Figure 1 (and thus the value of joining EMU) can be better assessed with the passage of time.

The impact of uncertainty and irreversibility on the entry decision can be formally illustrated using a standard investment model (see Appendix I). The main result of the model is that a simple net present rule is no longer a correct guide to the decision to join EMU. Given the opportunity cost of entering now rather than later (because of the option value of waiting for new information), it may be optimal not to enter now even if the net present value is positive. Moreover, the more uncertain the shape of the return curve, the higher should be the reluctance to enter. This raises a final issue:

Issue 12: what weight should be given to the value of more information that can be gathered with the passage of time?

\section{The Five TeStS AND THE TWelve ISSUES}

We now evaluate to what extent the Assessment addresses the above twelve issues. As we shall see, the Assessment's focus is uneven, with some issues explored at length and others discussed in considerably less detail.

\section{A. Issue 1: How Should the Entry Decision Problem be Formulated?}

As noted above, from an economic perspective, entry should occur at a time when the current NPV from the decision to enter (or its expected value in an uncertain environment, with appropriate corrections for risk-aversion) is maximized (equation 1 above). Were the five tests devised to solve this maximization problem? 
Figure 1. The Relative Return Curve
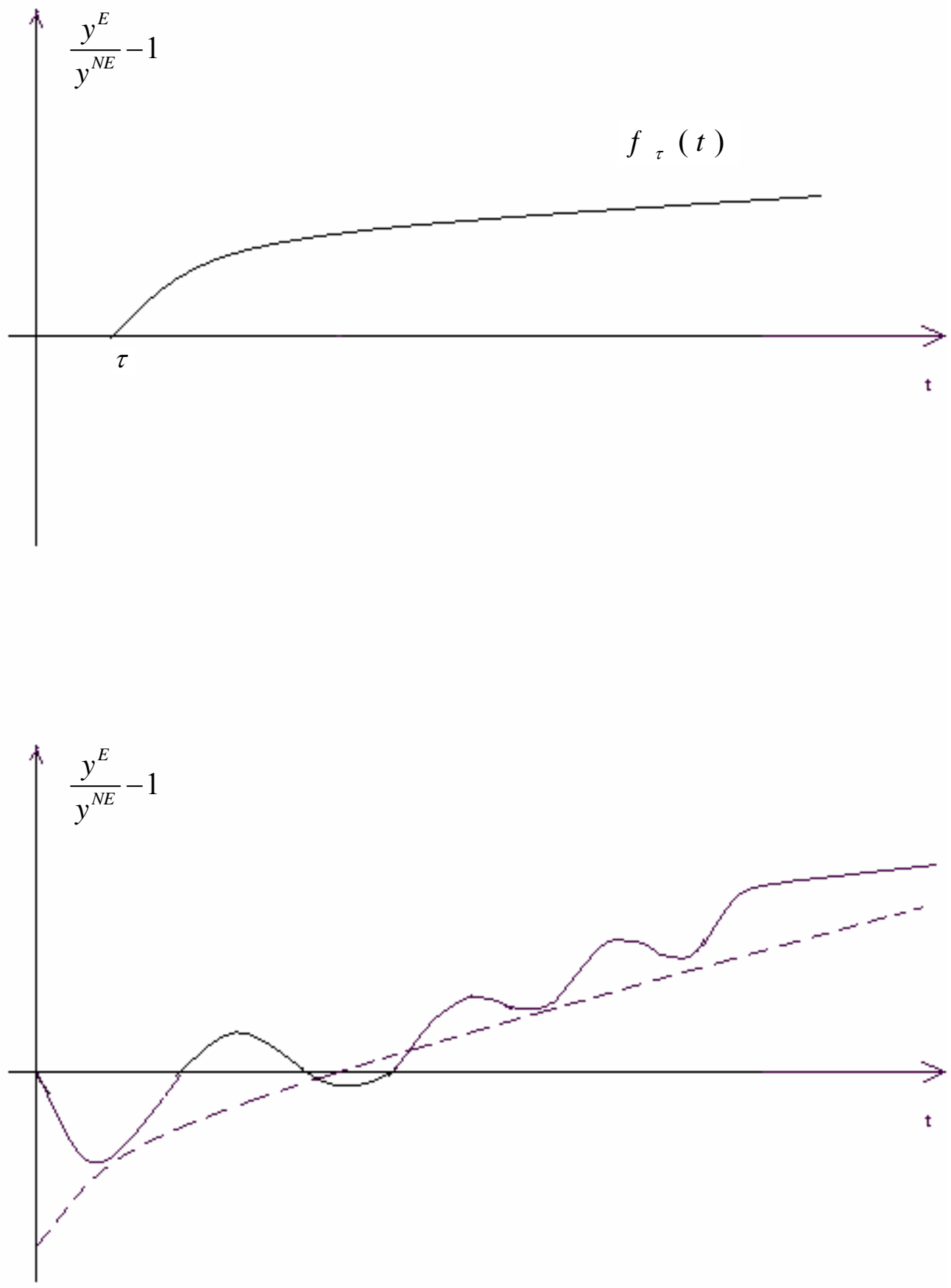
The U.K. government has stated it will support entry when, based on the five tests, the economic case for entry is clear and unambiguous. This could be taken as meaning that entry would be supported when the NPV from entry appears to be positive (in a clear and unambiguous way), and not when it appears to be maximized. But the alternative interpretation is possible, as the term "case for entry" is a rather loose one. A clarification of this point would thus be useful in a future assessment. In case the U.K. government has decided to follow the less ambitious benchmark - entry when the NPV is positive, rather than maximized - it would be useful to explain why. ${ }^{13}$

In a way, given the result of the Assessment, these issues may appear to be of a purely academic nature. The Assessment seems to suggest, although it is not explicitly stated, that the NPV from entry is currently negative (or more precisely that the case for a positive NPV is not yet clear and unambiguous), so entry would in no case be appropriate at this point. ${ }^{14}$ But clarifying the nature of the question the five tests are meant to answer would help in two respects. First, it will help interpret a future assessment. Second, it will provide better grounds for understanding the recent decision not to enter. Indeed, many of the arguments put forward in the Assessment are more convincing if used to justify the case that later entry will have a higher NPV, than if used to justify that the current NPV is negative ${ }^{15}$

\section{B. Issue 2: What is the Return from Entry Under full Convergence or Flexibility?}

Most of the work on the investment, financial services, and growth, stability, and employment tests (third, fourth, and fifth tests) relates to this question. We here focus on discussing Treasury's assessment of the effect of entry on growth (or income levels), a useful bottom line. ${ }^{16}$ The analysis is thorough and supports the conclusion that, under full convergence, the benefits in terms of output would be large.

${ }^{13}$ For example, one can argue that the complexity of the problem is such that maximizing the NPV is a futile exercise and one should be happy simply with being confident that the NPV is positive.

${ }^{14}$ For example $\$ 5.92$ argues that "additional volatility and uncertainty resulting from EMU membership in the absence of sustainable and durable convergence could have a negative impact on the actual level of UK output in the long term."

${ }^{15}$ One key argument in the Assessment is that the current idiosyncrasy of the UK cyclical position will lower significantly the potential benefits from entry. This could be a sufficient reason to delay entry to a more favorable cyclical juncture, if the criterion for entry is NPV maximization. But the argument is less credible if the criterion adopted is that the NPV should be positive, as the long term gains from entry are quite high (as discussed below). Arguing that these gains are more than offset by the short term costs of entering now is a more challenging task, that would require strong evidence that lack of current convergence also lowers significantly the long-term gains.

${ }^{16}$ Indeed, one could argue that the effect of entry on investment and financial services is relevant only in so far as the latter affect income levels, and that it would have been sufficient 
The Treasury's study covers a variety of channels though which entry could boost output growth. These include lower costs on cross-border transactions, lower exchange rate volatility, increased trade and competition, easier access to credit for at least some firms, and higher investment including inward FDI. These sources of growth interact and often overlap: for example, most of the benefits of lower exchange rate volatility are likely to work through increased trade. Double counting, however, is not a major problem since the output impact of increased trade alone appears to dwarf (and to some extent encompass) other factors. The Assessment estimates that: (i) under sustainable convergence, trade could rise by up to 50 percent over a 30 year period; and (ii) based on studies of the relation between trade and output levels, this would imply an increase in output over the same period of some 5-9 percent ( $\$ 5.68-\Phi 5.82$ and Box 1). Moreover, the evidence from the first few years since the euro's introduction indicates that the trade and output expansion might be frontloaded. ${ }^{17}$ Other positive effects are at least one order of magnitude smaller, but still far from negligible. For example, the step increase in output due to the fall in transaction costs is estimated at $0.1-0.2$ percent of GDP. ${ }^{18}$

These figures are even more impressive in terms of their NPV. Assuming that, following entry, the deviation of output from the baseline increases log-linearly during a 30-year horizon and then stays constant forever, the NPV of entering can be computed to be equal to 3-5 times current GDP at the time the decision is taken (corresponding to the 5-9 percentage point difference range in the output level). This assumes a real discount rate of $3 \frac{1}{2}$ percent, and reasonable base growth assumptions. ${ }^{19}$ Note that:

- This is likely to be an underestimate of the NPV under full convergence, first because it considers only gains arising from increased trade, and not from other sources; second because, as discussed, there is evidence that the effects on trade from a monetary union tend to be frontloaded.

- The NPV of the benefits of entry would not be greatly affected by a failure to reap the benefits of entry during a limited initial period - for example due to initial lack of convergence - provided this does not affect the outcome of later periods. In particular,

to assess whether the fifth test was met. However, the material discussed under the financial services and investment tests are also relevant to assess the effect on output.

${ }^{17}$ For example, the dynamic panel estimates in Micco, Stein, and Ordoñez (2003) suggest that more than $1 / 4$ of the long-run trade gains take place during the first year, and that the already realized gains in 2002 amounted to 4-10 percent of the estimated long-run gain of 34 percent.

18 The European Commission (1990) estimated the reduction in transaction costs at 0.4 percent of GDP if all EU countries adopted the euro. Savings, however, were thought to be smaller for large countries (with lower cross-border transactions-to-output ratios) and for currencies that were already traded in deep and efficient markets.

${ }^{19}$ Growth is assumed to be $2 \frac{1}{2}$ percent through 2012, and then as in HM Treasury, November 2003 PBR: "Long-Term Public Finance Report: Fiscal Sustainability with an Aging Population." 
the NPV of entry during the first ten years amounts only to between 8 and 15 percent of current GDP. In other words, the large magnitude of the NPV of entry stems from the hypothesis that the benefits are enjoyed at perpetuity, and not from the short-term gains. This is important in assessing the likelihood that high entry costs could outweigh the long term benefits. $^{20}$

\section{Issue 3: What is the Cost of Delaying Entry Arising from the Time Discount Factor?}

The time discount factor is not trivial. The appropriate time discount factor is the difference between the intertemporal discount rate and the output growth rate. Assuming this difference at 1 percent (as often done in long-term fiscal sustainability projections) implies that a fiveyear delay could reduce the NPV by over 5 percent. Thus, taking at face value the NPV estimate of the return under full convergence discussed under Issue 2, such delay would cost 15-25 percent of current GDP.

The Assessment does mention the existence of costs from delaying entry, but, with only two minor exceptions, it does so in an unspecific way. ${ }^{21}$ The first exception is the reference in \3.93 to the fact that:

There is a risk that the longer membership of the euro is delayed, the longer the potential gains in terms of increased inward investment are postponed. ${ }^{22}$

The second exception relates to the benefits from entry for the financial services industry, "benefits which are postponed while the United Kingdom is not in EMU” (ף4.70). These points are valid but should be made with respect to all gains from entry, in particular the expected increase in output levels discussed above. Moreover, no attempt is made to quantify those costs.

Neglecting the costs of postponing the benefits from entry would be justified only if it were true that the NPV from entry were assessed to be negative. This seems indeed to be the view adopted by the Assessment (see discussion above and issue 7 below). Thus, this omission can be pardoned only if the reasons for believing the NPV is currently negative are convincing.

\footnotetext{
${ }^{20}$ The Assessment, however, concludes that also the long-term benefits would not materialize in the absence of sustainable convergence (\$5.82). See discussion of issue 7.

${ }^{21}$ The Executive Summary states that: "The assessment addresses ... the risks and costs from delaying the benefits of joining" (page 4)." Later (page 6), it notes that the case for entry is not yet established, "despite the risks and costs from delaying the benefits of joining."

${ }^{22}$ The reference in $¥ 3.93$ to a "risk" is unfortunate. It is certain, indeed tautological, that the longer membership is postponed, the longer the potential gains from entry are postponed.
} 


\section{Box 1. Effects of EMU on Trade and Growth}

Until recently, the effects of currency unions on trade had generally been gauged as the limiting case of lower exchange rate volatility, with inconclusive results. The background study EMU and Trade (H.M. Treasury(2003b)) argues that these inconclusive results might be explained by an inappropriate focus on short-term volatility (which can often be hedged), while the relevant horizon for the creation of strong trade links is the medium to long term. Also, past volatility does not necessarily determine the degree of uncertainty on future exchange rate levels - as infrequent but large adjustments of fixed exchange rates epitomize.

A recent strain of research, prompted by the launching of the euro, has sought to identify the specific effect of currency unions. The opening shot was fired by Rose (2000), which finds that countries belonging to currency unions trade about three times more with each other than with non-members. The sample in Rose (2000) is dominated by economies that are small or have low income levels. But further research, focused on more relevant samples, has found estimates of the trade effect of EMU that are, although smaller, still very significant. Using quantitative meta-analysis techniques, Rose, in one contribution to the Treasury's assessment, synthesizes 443 point estimates from 24 recent studies into an estimate of a 100 percent increase in trade between EMU countries and the United Kingdom, should the latter join the euro. ${ }^{1}$ Recent studies have also tried to address different sources of upward estimation biases such as those resulting from adverse selection and simultaneity (e.g., countries that expect higher trade benefits will tend to form currency unions). ${ }^{2}$ After correcting for these biases, estimates of the trade effect of currency unions of 60-100 percent are not uncommon.

In order to avoid sample selection problems, some of the most recent studies take advantage of the already available evidence on the euro area and avoid drawing inferences from other currency unions. Instead, they focus on the actual effect that the introduction of the euro has had on its members as compared to those that stayed out. In this vein, Micco, Stein, and Ordoñez (2003) concludes that EMU membership shared by country pairs has already resulted in bilateral trade increases of 410 percent relative to all other country pairs in their sample; and 8-6 percent relative to trade between non-member country pairs. Remarkably, these results imply - in line with most other studies - that the trade increase among EMU members appears to have not been trade-diverting, but rather tradecreating among euro and non-euro members, albeit to a lesser extent than among members. These estimates correspond to the trade effects that had already taken place as of end-2002 - which can be presumed to be only a part of the total long-run effects. Using a dynamic panel, the long-run effect on a typical EMU-member country pair is estimated at a 34 percent increase in trade, with 9 percentage points in the first year. ${ }^{3}$ And the long-run effect on a pair with only one EMU member is estimated at 16 percent, 4.5 percent in the first year. The total effect of EMU on a member country's trade is the aggregate of the increase in trade with other EMU members and with third countries. Barr, Breedon, and Miles (2003) addresses directly the question of what would be the effect of joining EMU for the three "out" countries (Denmark, Sweden, and the United Kingdom).

${ }^{1}$ See Rose's contribution to the background study Submissions on EMU from Leading Academics (H.M. Treasury (2003b).

${ }^{2}$ For recent reviews of this literature see the background study EMU and Trade (H.M. Treasury (2003b), and Micco, Stein, and Ordoñez (2003).

${ }^{3}$ Bun and Klaassen (2002), with a similar methodology, find that the long-run trade gain is 40 percent, with 4 percent experienced in the first year. 


\section{Box 1. Effects of EMU on Trade and Growth (Concluded)}

Table 1. Implied Effect of Joining EMU (Barr et al. (2003))

( Increases in percent )

\begin{tabular}{|c|c|c|c|c|c|c|c|}
\hline & & \multicolumn{3}{|c|}{ Effect on Trade 1/ } & & \multirow{2}{*}{$\begin{array}{l}\text { Effect on } \\
\text { GDP 2/ }\end{array}$} & \\
\hline & & $\begin{array}{l}\text { Pure Currency } \\
\text { Union Effect }\end{array}$ & $\begin{array}{c}\text { Echange Rate } \\
\text { Volatility Effect }\end{array}$ & Total & & & \\
\hline Denmark & & 29 & 4 & & 33 & & 6 \\
\hline Sweden & & 29 & 20 & & 49 & & 7 \\
\hline United ingdom & K & 29 & 43 & & 72 & & 7 \\
\hline
\end{tabular}

Source: Barr et al. (2003).

1/ Increase in trade with EMU members.

2/ Assumes that 1 percent of GDP increase in trade results in 1/3 percent in crease in GDP, as in HM Treasury (2003b).

The results are summarized in Table 1 and generally support other studies, including the Treasury's conclusions of a 50 percent increase in trade. Barr, Breedon, and Miles (2003), however, finds that the quantitative estimates are sensitive to the sample length and Bun and Klaassen (2003) finds that they are also highly sensitive to the specification of time trends.

The relevance of trade derives mainly from its role in fostering output growth. There are many reasons to presume a positive effect of trade on output. These include the classical arguments for free trade (e.g., allocative efficiency) as well as those stemming from new growth theory (e.g., economies of scale, know-how and technology transfers and spillovers, increased competition and innovation, higher R\&D in internationally-oriented firms). The Assessment considers that this effect ranges between $1 / 3$ and $2 / 3$ of a percentage point of GDP per 1 percentage point of GDP in additional trade (imports plus exports). This is considered to be a one-time level effect, taking place over an extended period of time, and not a permanent change in the growth rate. These quantitative estimates fall comfortably within the range of estimates found in the research literature (see, for example, Frankel and Romer (1999), and Frankel and Rose (2000)). 


\section{Issue 4: How Does the Shape of the Return Curve Change over Time?}

The Assessment does point at one reason why later entry can improve the return for entry. The Executive Summary (page 6; but see also page 9 and $₫ 5.166$, as well as the more detailed discussion spanning $₫ 5.12-\uparrow 5.36)$, notes that:

The potential uncertainty created by the price stability objective of the European Central Bank (ECB) and the potential constraints on the use of fiscal policy for stabilization under the current interpretation of the Stability and Growth Pact (SGP) increase the chances that output and employment would be less stable inside EMU.

As the Assessment (page 6 of the Executive Summary) also notes that the monetary and fiscal frameworks are evolving in the right direction, late entry would allow participation in a monetary union that is managed though more appropriate rules. ${ }^{23}$ Assessing the validity of the argument - which hinges on the belief that the current monetary and fiscal frameworks of the United Kingdom are currently superior to those of the euro area-goes beyond the scope of this paper. Suffice it here to say that, even if it were correct, the argument would be inherently difficult to quantify in a number of respects (notably the pace of expected improvement over time of the euro framework, and the effect of this improvement on output volatility).

The factors that may reduce the return from entry are not discussed in the Treasury's assessment. However, euro-supporters have pointed at the risk of "missing the train" if entry were delayed. The basic argument, made for example by Professor Richard Layard (Layard (2002)), is that euro area will experience (indeed is already experiencing) a front loaded relocation of productive activities and the establishment of new business contacts, accompanying the surge in intra-euro area trade. ${ }^{24}$ As Layard's puts it:

We cannot wait and see because, by the time we joined, the new pattern of the European economy would have been established. It would be much harder then than it would be now to find our own niche.

The argument is not far fetched. First, FDI may flow more than before to the euro area (see Appendix II). If this relocation of investment decision does not occur evenly over time, but is front loaded, countries that are not euro-members in the early years of the euro area will miss

\footnotetext{
${ }^{23}$ Note that this applies also to the fiscal framework. As a non-euro EU area member, the United Kingdom is now expected to endeavor to avoid deficits exceeding 3 percent of GDP, while, in principle, would be obliged to avoid breaching that ceiling once in the euro area (as highlighted in $\$ 5.36)$.

${ }^{24}$ The costs of a delay in joining EMU are also analyzed in Begg et al. (2003).
} 
the first and larger wave of FDI. ${ }^{25}$ Second, the quantitative estimates of the trade expansion prompted by EMU do suggest that this expansion is also frontloaded. Then, hysteresis effects in international trade links may make it difficult to enter new markets once they are settled. Although, ultimately, the trade opportunities opened to the United Kingdom will depend on comparative advantage, in the short and medium term, expansion into new EMU markets would be facilitated by joining when these markets are undergoing an expansion or, at least, a reshuffling. Altogether, a discussion of these issues would have strengthened the quality of the Assessment.

\section{E. Issue 5: How Convergent Is the U.K. Economy With Respect To the Euro-Area Average, in Terms of Both Idiosyncratic Shocks and Idiosyncratic Transmission Mechanism?}

Many of the background studies in Treasury (2003b), and most of the material on the "convergence test" in the Assessment cover extensively different aspects of these issues. ${ }^{26}$ More specifically, the Assessment looks at the differences in the current cyclical phase between the United Kingdom and the euro area ( $\mid 1.8-\Phi 1.40)$, evidence of past correlation of business cycles and shocks ( $\mid 1.40-\uparrow 1.65)$, and underlying differences in the structure of these economies ( $\mid 1.69-\Upsilon 1.116)$. Overall, the Assessment finds that convergence has increased since 1997, but is still insufficient. The key idiosyncrasies arise from differences in housing and households credit markets. ${ }^{27}$ On the one hand, the link between consumption and house price movements in the United Kingdom appears to be particularly strong and has added an element of U.K.-specific cyclicality to regular business cycles. On the other hand, the large size of the mortgage market, as well as its specificities, have raised the elasticity of consumption to interest rates above the euro average. In sum, the peculiarities of the housing

${ }^{25}$ As discussed above, $₫ 3.93$ does note that the longer entry is delayed, the longer the potential gains in terms of FDI are postponed. But this is not the cost we are referring to here. With respect to the analytical framework used here, $\$ 3.93$ focuses on the cost of shifting the return curve to the right (Issue 3 above), not to the change in the shape of the return curve (Issue 4).

${ }^{26}$ See "Analysis of European and UK business cycles and shocks"; "Housing, consumption and EMU"; "EMU and the monetary transmission mechanism"; "Modelling the transition to EMU"; "Modelling shocks and adjustment mechanisms in EMU"; "EMU and labour market flexibility"; "The exchange rate and macroeconomic adjustment"; "The United States as a monetary union"; "Submissions on EMU from leading academics"; "Fiscal stabilisation and EMU"- - a discussion paper in Treasury (2003b). For an earlier discussion see IMF (2000).

${ }^{27}$ Discussing the risks to convergence posed by structural differences, the Assessment states that "differences in the UK and euro area housing markets are high risk, differences in investment linkages and financial structures are low to medium risk and sectoral and trade differences are lower risk.” (\$1.112). 
and household debt market not only give rise to idiosyncratic shocks, but also generate an idiosyncratic response to monetary policy shocks. The current cyclical phase epitomizes these developments (Box 2).

The case made by the Assessment that the features of the housing market involve the risk of significant idiosyncratic shocks is convincing. Less convincing is the case that these features also involve an idiosyncratic response to monetary policy impulses. The Assessment does show that monetary policy has a stronger effect on consumption in the United Kingdom than in the average of the euro area. But, it also acknowledges that the effect of monetary policy on aggregate demand is similar, as the higher elasticity of consumption to interest rates is offset by lower elasticity of investment. ${ }^{28}$ Thus, assuming that total demand, rather than just consumption, is the relevant determinant of inflationary pressures, an optimal response of monetary policy to demand shocks that are common between the United Kingdom and the euro area would be possible.

\section{F. Issue 6: How Flexible Is the U.K. Economy and, Relatedly, How Much Flexibility Is Needed to Compensate for Imperfect Convergence?}

The discussion of the degree of flexibility the U.K. economy spans nearly 60 pages of the Assessment. It deals primarily with wage and price flexibility, but also covers other aspects of labor and product markets, such as geographical/sectoral labor mobility, and of the capital market. Finally, the Assessment discusses to what extent a more flexible use of fiscal policy, within a revised fiscal framework, could compensate for the loss of monetary flexibility. The discussion is thorough and succeeds in showing that U.K. flexibility has improved and is high compared with other European countries. The case is also made (although it is backed up by less detailed discussion) that "challenges remain" in the labor market (see, for example, $\mid 2.83$ ), and that product market flexibility is still not as high as in the United States ( $\mid 2.111$, for example).

But the conclusion of the Assessment - that flexibility is not sufficient to compensate for the insufficient convergence-is not clearly demonstrated. How much flexibility is needed? ${ }^{29}$

\footnotetext{
${ }^{28}$ This lower elasticity is usually explained by the higher resort to long-term capital markets financing — as opposed to bank lending — by UK firms and by higher external financing.

${ }^{29}$ A section of the assessment ( $\left.\ 2.29-2.33\right)$ is titled: "How much flexibility is needed in principle?" However, it primarily deals with the effect that increased flexibility would have on inflation volatility, and with implications for macroeconomic management of different degrees of flexibility between the United Kingdom and euro-area members.
} 


\section{Box 2. Consumption and the Housing Market}

Private consumption has been the main driver behind U.K. demand growth during the 1990s. The contribution of private consumption to GDP has been significantly larger in the United Kingdom than in the euro area in the period 1992-2002 (except in 1992 and 1995) with annual average contributions of 2.1 and 1 percentage points of GDP respectively (Figure 2). This is not only because GDP grew faster in the United Kingdom: Figure 3 shows that private consumption contributed also substantially more to each percentage point of GDP growth in the United Kingdom than in the euro area in all years in 1992-2002 (except 1995).

This strength of consumption has been supported not only by rising incomes and high rates of employment, but also by the dynamics of the housing market. In the United Kingdom, the evolution of consumption has been closely correlated with the housing market, at least since the 1960s (Figure 4), and to a larger extent than in other EU economies (Figure 5). Research studies have documented the differential responsiveness of consumption to housing wealth in the United Kingdom relative to other countries. ${ }^{1}$ These studies generally find that the elasticity of consumption to real house prices is larger in the United Kingdom, Ireland, Netherlands, and some Nordic countries than in the large euro-area economies.

Different consumption responses to changes in house prices appear related to different features of the housing and financial markets. First, owner-occupied housing is more prevalent in the United Kingdom, at 69 percent, than in large euro-area countries (Table 2), strengthening the wealth effects of house price changes. ${ }^{2}$ Second, highly developed mortgage and credit markets as well as deep and liquid housing markets (Table 2) allow U.K. households to cash in housing wealth increases through trade-downs or, more often, through mortgage equity withdrawal (house-collateralized borrowing in excess of spending in residential purchases and house improvements). And finally, increases in housing wealth coupled with the opportunity to withdraw housing equity also relax liquidity constraints.

Moreover, the housing market itself seems to be characterized by idiosyncratic features. Real house prices in the United Kingdom have shown higher trend growth and higher volatility than in the euro area, ${ }^{3}$ partly reflecting a relatively price-inelastic supply. ${ }^{4}$ This has made U.K. housing prices more sensitive to demand shocks and to potential bubbles. Also, error-correction models indicate that U.K. housing prices exhibit high persistence. Thus, following a deviation from trend, re-equilibrating forces are weak - resulting in prolonged over- and under-shooting (IMF (2002) and Housing, consumption and EMU (HM Treasury (2003b)).

${ }^{1}$ Recent work is discussed in detail in Housing, consumption and EMU (H.M. Treasury (2003b)). See also Ludwig and Slk (2002).

${ }^{2}$ House price increases prompt both positive and negative wealth effects, since they result in a redistribution of wealth from first-time buyers (and those trading up) to house owners. This, and a relatively limited mortgage market, could be behind a low or negative elasticity of consumption to house prices, which for example is often estimated for Italy. In most EU countries, positive wealth effects are found to predominate. 


\section{Box 2. Consumption and the Housing Market (Continued)}

This behavior of consumption and housing markets has also an important bearing on the response of the economy to monetary policy. Empirical studies indicate that U.K. private consumption is more responsive to interest rates, reflecting several factors. ${ }^{5}$ First, the policy rate pass-through to banks' lending rates appears quicker in the United Kingdom, with variable-rate mortgages reacting typically in just a few days. ${ }^{6}$ Second, household exposure to variable-rate debt is higher in the United Kingdom than in most other EU countries. This is mainly due to the structure of the mortgage market. The outstanding stock of mortgages is about 60 percent of GDP in the United Kingdom, most of which are at variable rates or with rates fixed only for a few initial years (Table 2). In contrast, mortgages represent 19 percent of GDP in France and 10 percent of GDP in Italy. They represent a higher proportion in Germany (55 percent of GDP), but it appears that a large part are held by for-rent landlords (owner-occupied housing is a low 42 percent), and long-term fixed rate mortgages prevail (as they do in France, Netherlands, Belgium, Denmark and other EU countries) — thus, minimizing the direct impact of interest rate changes on household consumption demand. ${ }^{7}$ And third, a more diversified financial market allows U.K. households to realize more easily part of their housing wealth gains through mortgage equity withdrawal.

${ }^{3}$ Over the long run, U.K. real house prices have grown at 3.3 percent, perhaps the fastest rates in the EU (see Table 2 ), and significantly faster than Germany ( 0.1 percent), France ( 1.2 percent), and Italy (1.5 percent). U.K. house prices have also been more volatile than in France and Germany, although not out of line with respect to some other EU countries (i.e., Spain, Italy, the Netherlands, Ireland, and Finland).

${ }^{4}$ See IMF (2003). Swank et al. (2002) estimates the following price elasticities of new housing supply: Denmark 0.7, France 1.1, Germany 2.1, Netherlands 0.3, United Kingdom 0.5, United States 1.4.

${ }^{5}$ See EMU and the monetary transmission mechanism (H.M. Treasury 2003b).

${ }^{6}$ Estimates of the pass-through of one percentage point increase in policy rates to variable-mortgage rates after three months are: United Kingdom 0.97, Germany 0.78, Italy 0.62, Spain 0.66, and France 0.33 (EMU and the Monetary Transmission Mechanism (H.M. Treasury (2003b)).

${ }^{7}$ Taking into account only the share of mortgages in GDP and the proportions of variable-rate mortgages, EMU and the Monetary Transmission Mechanism (Chart 3.6, HM Treasury (2003b)) estimates that the impact on household spending of one percentage point rise in interest rates is about (in percentage points of GDP): United Kingdom 0.37, France 0.07 , Italy 0.03 , and virtually nil in Spain and Germany. These estimates may still underestimate the U.K. idiosyncrasy, however, as they do not consider, inter alia, owner-occupancy rates or faster pass-trough into mortgage interest rates. 


\section{Box 2. Consumption and the Housing Market (Concluded)}

Table 2. Selected Housing Market Features

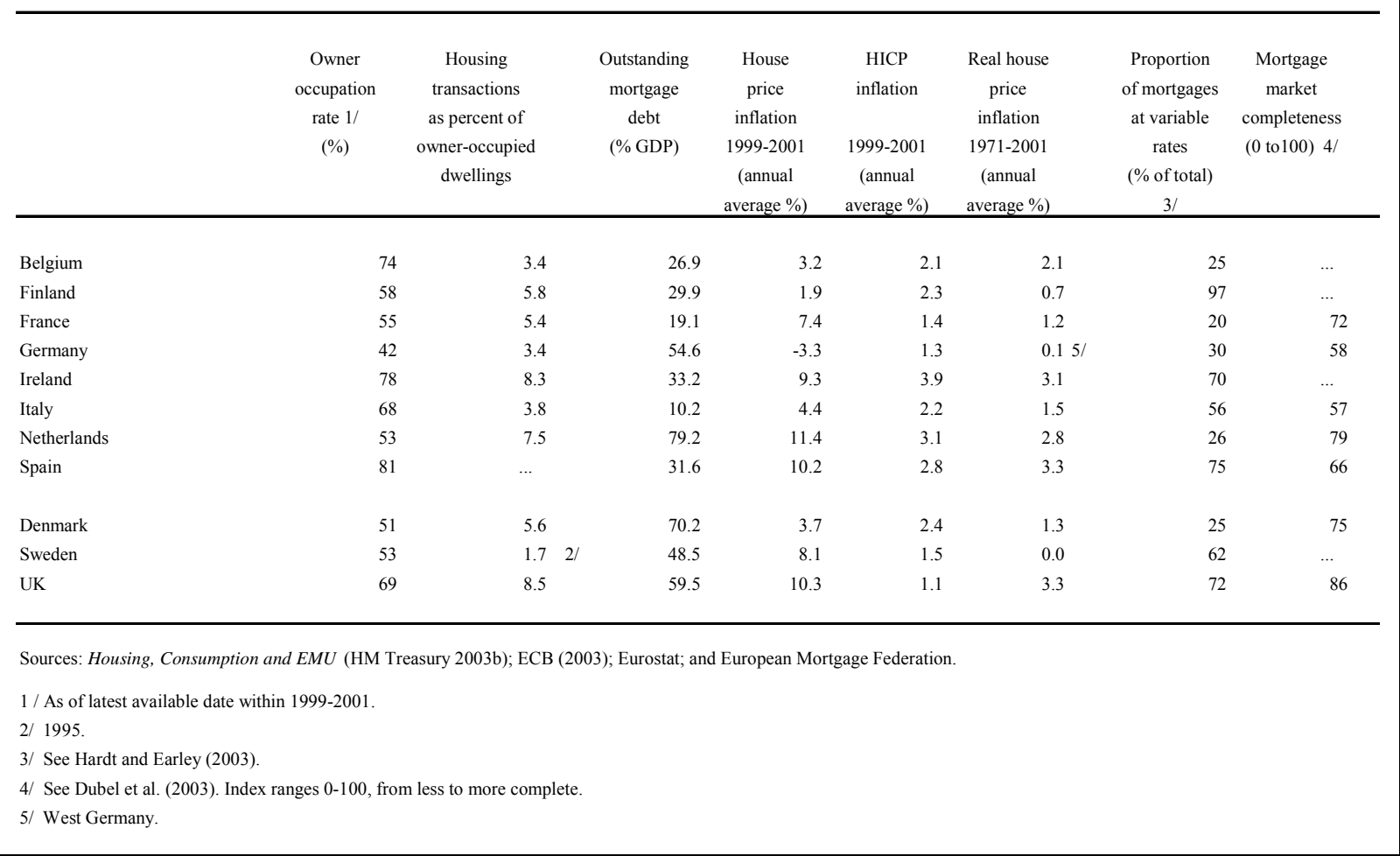

How much is the United Kingdom away from the degree of flexibility needed to compensate for imperfect convergence? More generally, how much increased flexibility is needed to offset differences in the degree of convergence? And how much can further progress in reforming the U.K. economy over the next few years buy in terms of increased flexibility? These questions are not addressed directly. ${ }^{30}$ Answering these questions is not, and will not be, easy. This is an area where informed judgment, rather than precise economic calculations, will remain inevitable. Waiting will likely improve flexibility further, which will help, but the marginal benefit of waiting is hard to assess.

${ }^{30}$ As to indirect approaches, the "what if" simulations presented in the Assessment regarding the effect of euro-entry in 1999 do show that entry at that time would have increased output volatility, which could imply that flexibility was not yet sufficient to compensate for the loss of monetary independence. But those simulations are necessarily based on models estimated on historical data and, thus, cannot evaluate the effect of the increased flexibility and convergence of the UK economy since 1997. The same argument can be made with respect to the discussion in $92.34-2.40$, which takes a similar model-based approach. 


\section{G. Issue 7: What Is the Effect of Output Volatility on Average Output Growth?}

This issue plays a key role in Treasury's assessment. Given the huge potential output gains from entry under full convergence, and the fact that the NPV from entry is very much affected by what happens in the long run, rather than what happens in the short run, it would be hard to argue that the NPV turns negative only as a result of the welfare costs arising from output volatility (see discussion of issue 8), or of the one-off entry costs if entry takes place at the "wrong time" (see discussion of issue 11). However, the Assessment takes the view that average output growth over the next decades, would be much lower in the absence of full convergence. ${ }^{31}$ Indeed, it explicitly indicates that, in the absence of sustainable convergence, entry could have a negative impact on the level of U.K. output in the long term ( $\$ 5.92)$. It follows that to reap the growth-enhancing benefits from euro entry, a sufficient degree of convergence must first be secured. This is the essence of the conclusion that the investment and growth tests would be met only if the convergence test is met.

The Assessment does not elaborate much on why sustainable convergence is a condition for reaping the output benefits from euro entry. However, this link seems obviously to be provided by the fact that, in the absence of convergence, output growth would be more volatile, and output volatility would depress average output growth. This interpretation is consistent with several passages of the Assessment. ${ }^{32}$

The existence, in principle, of a link between stability (or its counterpart output volatility) and potential growth is hardly contentious. The more interesting issue is, however, by how much increased output volatility lowers potential growth, and whether this effect is linear or not (for example, whether it is negligible below a certain volatility threshold). Given the role that this link is playing in the Assessment, it would have been useful to provide a clear discussion of this point. ${ }^{33}$

${ }^{31}$ In particular, the assessment takes the view that the benefits arising from increased trade would accrue only in the presence of sustainable convergence: Without the maintenance of continued stability, the trade benefits of joining EMU would be negligible. ( $\mid 5.82$ )

${ }^{32}$ For example, $\mid 5.2$ notes that one of the pillars of the UK government's strategy to increase output and productivity has been "maintaining macroeconomic stability". Indeed, stability "helps individuals and business to plan for the longer term, improving the quality and quantity of investment in the economy, and helping to raise productivity and the sustainable rates of growth and employment" (\$5.12).

${ }^{33}$ Cross-country evidence of the detrimental effect of volatility on growth is presented, for example, in Ramey and Ramey (1995). The latter finds that volatility has a strong negative effect on growth. However, it does not focus on whether the effect of volatility on the level of output is permanent or temporary. The relation between volatility and growth in the context of the UK EMU decision is discussed in Barrell (2002) and Pain (2002). Barrell 


\section{H. Issue 8: What Is the Welfare Cost of Increased Output Volatility?}

Increased output volatility has a cost per se as people dislike volatility. Quantifying this effect is not easy, and the assessment does not address this issue. However, following the approach in Lucas (2003), one should conclude that the welfare cost of volatility, while not trivial, should not be overemphasized. As detailed in Box 3, even assuming a strong aversion to risk, and a fairly sizable increase in volatility, the cost of volatility, in terms of consumption-equivalent, would be of the order of 0.1 percent of GDP on an ongoing basis (or, in terms of NPV, a one-time loss of 101/2 percent of GDP, at a discount rate of $3 \frac{1}{2}$ percent). This might underestimate the true costs for the society if allowance were made for the higher costs that output volatility would cause to lower income/liquidity constrained individuals. On the other hand, because of endogenous convergence, volatility is unlikely to remains permanently higher. In any case, the figure is dwarfed by the potential gains from entry under convergence estimated above (3-5 times GDP).

\section{Issue 9: How Fast Is Endogenous Convergence?}

The Assessment acknowledges that endogenous convergence-first of policies, and, over time, of economic structures through increased trade and investment links - is likely, and that this would reduce the risks from entry $(\mathbb{\$} 1.117-1.132)$. It also points at evidence on increased intra euro-area trade as the force that will foster convergence. It, however, concludes that endogenous converge will operate only gradually and thus will not help in reducing the initial shock from EMU entry (see issue 11 below). The discussion of endogenous convergence is less extensive than other parts of the Assessment, but one has to acknowledge that, just a few years after the beginning of EMU, it is hard to evaluate how fast endogenous convergence is proceeding. This is an area where the passage of time will allow gathering more specific information.

indicates that volatility in nominal macroeconomic variables has had a larger effect on UK growth than real volatility. Both types of volatility, however, have been closely correlated in recent times making it difficult to discriminate between their specific effects. 


\section{Box 3. Quantifying the Welfare Cost of Output Volatility}

The discussion here follows the approach proposed in Lucas (2003). Consider the simplest representation of an intertemporal utility (welfare) function with risk aversion:

$$
W_{0}=E\left\{\sum_{t=0}^{\infty}(1 /(1+\rho))^{t} \frac{c_{t}^{1-\gamma}}{1-\gamma}\right\}
$$

where the parameter $\gamma$ represents risk aversion, with typical estimates ranging between 1 and 4 ; the time discount $\rho$ can be set at $3 \frac{1}{2}$ percent as in the long-term public finance analysis used by the U.K. Treasury in the documents accompanying the 2003 Pre-Budget Report. For analytical purposes, one can assume the stream of consumption $c_{t}$ to be deterministic in case the United Kingdom stays out of EMU (say $c_{t}=A e^{\mu t}$, with growth $\mu$ at $2^{1 / 2}$ percent). If the United Kingdom joins EMU, consumption is assumed to be subject to random shocks:

$$
c_{t}=B e^{\mu t} e^{-0.5 \sigma^{2}} \varepsilon_{t}
$$

with the logarithm of $\varepsilon_{t}$ normally distributed with 0 mean and $\sigma^{2}$ variance. Then $\sigma^{2}$ is the variance introduced in the consumption stream $c_{t}$ by EMU entry (that is, the variance of the logarithm of consumption around its trend). For the consumer to be indifferent between the entry and no-entry alternatives, the random consumption stream under entry should be higher, on average, than the deterministic consumption stream. The proportion $\lambda$ by which the random consumption stream must be larger, on average, than the deterministic stream indicates the cost of volatility from EMU entry. An approximate expression for lambda is $\lambda \approx 0.5 \gamma \sigma^{2}$ which is proportional to the risk aversion and the volatility introduced by euro adoption. For example, if the risk aversion is 4 (high, but within a reasonable range), and the volatility is set at 0.0004 - equivalent to an increase in the standard deviation of consumption of 2 percentage points of consumption, in line with the EMU assessment simulations, then $\lambda$ equals 0.08 percent. That is, consumption should be higher, on average, by 0.08 percent after entering EMU to compensate for an increase in volatility of about 2 percentage points of consumption. This is a very small number. However, consideration should be given to several factors - such as distributional inequalities, liquidity constraints, etc.which could increase the losses from more volatility for some consumers. 


\section{J. Issue 10: How Much Can Be Gained In Terms Of Improved Convergence and Increased Flexibility as a Result of Waiting (as Reforms are Implemented)?}

As a result of the Assessment, and in order to facilitate any possible entry at a later date, the U.K. government has taken or started considering some reform steps aimed at facilitating convergence. Moreover, it is continuing its underlying effort to increase the flexibility of the U.K. economy. Critics of this approach have noted that the reforms that are being considered will inevitably take time to be implemented and, even more, to have effect. ${ }^{34}$ Things are unlikely to change rapidly in just a few years. Thus, unless entry is postponed by several years, waiting will not make much difference. Whether this is a valid point depends on the actual reforms that will be implemented, in particular to reduce the idiosyncrasies in the behavior of the housing market. But the specific nature of the reforms is not yet known, and thus it is difficult to draw a conclusion on this issue.

\section{K. Issue 11: Is the case for No Entry Made Stronger by Current Idiosyncratic Shocks?}

Large idiosyncratic shocks are unlikely to be frequent. Thus, the case could be made that it is unwise to enter at a time when a large idiosyncratic shock is in progress. The NPV from entry could be raised by entering after the idiosyncratic shock is gone. Endogenous convergence, boosted by reform, will make sure that later idiosyncrasies are less relevant.

Developments in housing and household debt market in the last few years do suggest that the United Kingdom is currently affected by a strong idiosyncratic shock and that, as a result, euro-area interest rates would currently be particularly inappropriate, giving rise to high entry costs (Box 4). ${ }^{35}$ It could be argued that, given the present phase of the U.K. housing cycle and the sensitivity of consumption to short-term interest rates, the monetary impetus that EMU entry would imply could destabilize the U.K. economy over a medium-term transition

\footnotetext{
${ }^{34}$ See, for example, the article by Ed Crooks, Economic Editor of the Financial Times, in the Financial Times of June 11, 2003 (A year may be a short time in five-test politics)

${ }^{35}$ In principle, significant costs would also arise in case entry occurred when the exchange rate is being hit by a strong shock (that is, when it is far away from equilibrium, assuming that entry could not occur at a rate that is too different from the market rate). Indeed, as recalled in 91.134 , in one of the EMU studies Professor Mundell notes that: "The issue of timing is important. If Britain enters when its economy is in a strong boom compared to Europe, the pound would be high against the euro, and that might in the long run put Britain at a competitive disadvantage." The weakening of sterling since early 2003 has reduced the practical relevance of this issue for the moment. Thus, while the Assessment pays quite a lot of attention to it ( $\mid 1.133-1.151)$, the discussion of the transition costs primarily focuses on the implications of lowering interest rates at a time when a housing and households debt boom is in progress.
} 
period, as it could exacerbate the housing and consumption boom and make more likely a later abrupt correction, as occurred in the late 1980s and early 1990s.

This argument seems to have played an important role in leading to the conclusion that entry is not appropriate at this stage. $\uparrow 1.152-1.163$ focus on this issue and, specifically, on the $1 \frac{1}{4}$ percentage point fall in interest rates (the interest rate differential when the Assessment was published) that would arise from euro entry. ${ }^{36}$ Also, the Assessment includes an extensive discussion of what would have happened if the United Kingdom had joined in 1999, when the differential was even larger (Box 4). Altogether, the case that entering now would involve higher costs with respect to entry when cyclical conditions are more favorable is reasonable. Of course, this is not to say that these costs are sufficient to make the NPV from entry negative, nor that entry at a later date has a higher NPV, as the lower costs of entry would have to be assessed against the costs of delaying entry discussed above.

The Assessment also discusses the policy options to reduce the euro entry shock, including a fiscal tightening aimed at offsetting the expansionary effects of the monetary relaxation. ${ }^{37}$

However, the feasibility of this change in the policy mix is not fully explored. The Assessment argues that there is some uncertainty on the scale of the needed fiscal tightening ( $\ 1.162)$ and that "the first best solution is to ensure economic conditions are sustainable at entry" ( $\mid 1.163)$. Admittedly, calibrating the appropriate degree of fiscal tightening would have not been easy, given the potential nonlinearities that may arise in the presence of an asset price bubble. However, the Assessment could have clarified why only the "first best solution" was regarded as feasible, in spite of the potential costs of delaying entry.

\section{Issue 12: What Weight Should Be Given to the Value of More Information that Can Be Gathered with the Passage of Time?}

The value of additional information that becomes available over time on issues relevant for the entry decision is not explicitly appraised in the Assessment. However, this is an underlying theme in the U.K. government approach to the decision. Indeed, the very idea that entry will take place when the case is established in a clear an unambiguous way can be related to the desire to acquire sufficient information on the effects of entry on the U.K. economy before an "irrevocable" decision is taken ( 9.10$)$.

\footnotetext{
${ }^{36} \$ 1.117$ notes that the mechanism of endogenous convergence that can reduce the costs from entry over time would not alleviate the costs related to the immediate "shock of entry."

${ }^{37}$ Box 1.8 in the Assessment provides an estimate of the reduction in government spending that might be necessary. Also, one of the background studies includes a detailed estimate of the percentage cut in government spending (about 6 percent) that would be required to offset the relaxation of monetary conditions caused by EMU entry (see Wren-Lewis, S. (2003)).
} 


\section{Box 4. Is the United Kingdom Currently Affected by an Idiosyncratic Shock?}

Since their trough around 1996, U.K. annual real house price increases have averaged close to 10 percent, reaching a deviation from their (log-linear) trend of about 30 percent by mid-2003 (Figure 6). An update of the estimates in IMF (2002) also indicates a similar overvaluation of 2003 U.K. house prices relative to their long-run equilibrium - as determined by real disposable income per household and real interest rates. As the rise in house prices contributed to the strength of aggregate demand, U.K. policy and short-term market interest rates have remained on average $1 \frac{1}{2}$ percentage points above those of the euro area since 1999. In fact, given inflation differentials, the average gap in short-term real interest rates since January 1999 between the United Kingdom and the euro area has been about $2 \frac{1}{2}$ percentage points.

Several background studies in H.M. Treasury (2003b) undertake extensive simulations of the impact that joining EMU would have had under these circumstances on the basis of large-scale macroeconometric models and of structural vector auto-regressions. ${ }^{1}$ Overall, the results indicate that output and inflation volatility would have increased significantly. For example, the Assessment (H.M. Treasury (2003a)) reports the simulation of a counterfactual U.K. entry at the time of the launching of the euro in 1999, based on the NiGEM model of the National Institute of Economic and Social Research (NIESR). This simulation indicates that output growth would have been about 2 percentage points higher in 2000 , followed by a $1 \frac{1}{2}$ percentage points lower growth by 2002 , which would have remained significantly lower over the medium term. Also, inflation would have been $4 \frac{1}{2}$ percent by end-2000, with real interest rates remaining negative until mid-2003. Thus, adopting the prevailing euro-area interest rates would have resulted in a sizable inflationary stimulus and, since nominal interest rates would only have reacted mildly, U.K. real interest rates would have declined further, additionally stimulating the economy. Eventually, the re-equilibrating process would have gathered pace through a real exchange rate appreciation and losses in competitiveness, with inflation, output, and employment variation taking most of the burden of adjustment.

But informative as these simulations are, they do not capture the risks of nonlinearities and abrupt corrections that could result from the housing and credit markets developments discussed above. Results from standard statistical techniques are better interpreted as representing an average (essentially linear) response based on past behavior averaged over a long period of time. But, in practice, as the correction in real house prices at the end of the 1980s exemplifies, re-equilibrating forces may first lag the evolution in fundamentals and then manifest abruptly, resulting in a protracted period of depressed demand.

${ }^{1}$ See Modelling the Transition to EMU and Modelling shocks and adjustment mechanisms in EMU (HM Treasury (2003b)). The models used include the Treasury Public Model, the NIESR's NiGEM, IMF Multimod, and a specifically constructed "Three Bears Model"- so called because it consists of a small economy (United Kingdom), a medium-size economy (the euro-area), and a large economy (the rest of the world). 
More generally, the high uncertainty surrounding the quantitative estimates provided in the Assessment may have played an important role in influencing the overall conclusion that the economic case for entry is not yet established in a clear and unambiguous way. If taken at face value, the gains from entry under full convergence are so high ( 3-5 times current GDP) that it is hard to believe that they could be fully offset (so that the NPV from entry becomes negative) when the hypothesis of full convergence is relaxed. However, even with a positive expected NPV, the decision to delay entry could be justified by arguing that the assessment of the gains under convergence, even when expressed in terms of ranges, remain subject to a high degree of uncertainty. Indeed, available evidence provides only a partial view of the long-term effects of EMU and research in this area is still in its incipient stages. In particular, the mechanisms by which currency unions foster trade and output are not yet well understood, especially at the microeconomic level (a point the Assessment does not fail to make; see 95.78). More information on the effects that EMU is having on its current members would also allow a better assessment of the effect that entry would have on the United Kingdom. This highlights the value of waiting and may provide an alternative way of interpreting the conclusion that the five tests have not yet been met.

It is not clear to what extent this argument played a role in informing the actual decision that entry at this stage would not be appropriate. A more thorough discussion of this issue would have facilitated the interpretation of the decision not to enter.

\section{Conclusions: Seven Areas For Further Work}

The breadth and depth of the Assessment prepared by the U.K. Treasury is impressive by any standard. The sheer length of the Assessment and background studies (reportedly some $1 \frac{1}{2}$ million words) ${ }^{38}$ seems unprecedented for an economic decision of this kind. The Assessment deals with most of the issues relevant for thoroughly assessing the case for euro entry and its conclusions are typically backed up by state-of-the-art economic reasoning and empirical evidence. This includes the analysis of the long-term benefits from increased trade, growth, and employment arising from full convergence; the evaluation of entry costs, at a time when the U.K. economy is in a different cyclical position than the euro area, reflecting a strong idiosyncratic shock; the evaluation of the potential risks over the medium term from the loss of monetary independence; and the thorough evaluation of the structural degree of convergence and progress in flexibility since the 1997 Assessment.

A future assessment could, however, benefit from a more complete discussion of several important issues that the Assessment does not fully cover. To start with, it would be useful to clarify, particularly with respect to the issue of the most appropriate timing of entry, the analytical framework from which the five tests are derived, since that would provide a clear "checklist" of all the issues relevant to the entry decision. We have attempted to provide a framework for such a decision in Section II above, and this has allowed us to identify the

${ }^{38}$ See Financial Times, "Euro rows to go on as Brown puts off verdict," June 10, 2003. 
areas that could have been covered more thoroughly. They relate particularly to the following:

- The question of whether entry is expected to take place when the return from entry is positive or when the return from entry is maximized. This distinction is important, since in many ways, the arguments that the Assessment advances are more convincing if used to argue that later entry will have a higher return than that entry now would have a negative return.

- The quantification of how much insufficient convergence would lower the long-run benefits from entry in terms of higher trade and growth.

- The reasons why flexibility is not regarded to be sufficient and, relatedly, the parameters by which sufficient flexibility should be assessed.

- The discussion of the costs of delaying entry arising from the time discount factor and from missing the chance to enter during a phase when the new business structures that are forming as a result of increased intra-euro-area trade have not yet crystallized.

- The reasons why the differences in the speed of the transmission mechanism with respect to consumption are regarded as problematic in spite of evidence that the elasticity of overall demand in the United Kingdom seems to be close to the euro-area average.

- The costs that arise from higher output volatility per se, regardless from the effect that output volatility may have on output growth.

- The policy options to reduce the euro entry shock, in particular the possible change in the policy mix in case entry should occur when interest rates in the United Kingdom are higher than in the euro area.

A more thorough discussion of these seven points would not necessarily have changed the conclusions of the Assessment. But it would have strengthened any conclusions reached.

At the same time, we have highlighted that in many of the areas that are relevant for euro entry, including many of those summarized above, in spite of any reasonable attempt, the margin for uncertainty will remain significant. Further work can reduce the uncertainty, but not eliminate it altogether. In a way, as is true of most economic decisions, the case will never be "clear and unambiguous." Indeed, it could be argued that for a complex decision of this kind, a more realistic benchmark should be to condition entry on the existence of a sufficiently clear and unambiguous economic case. 


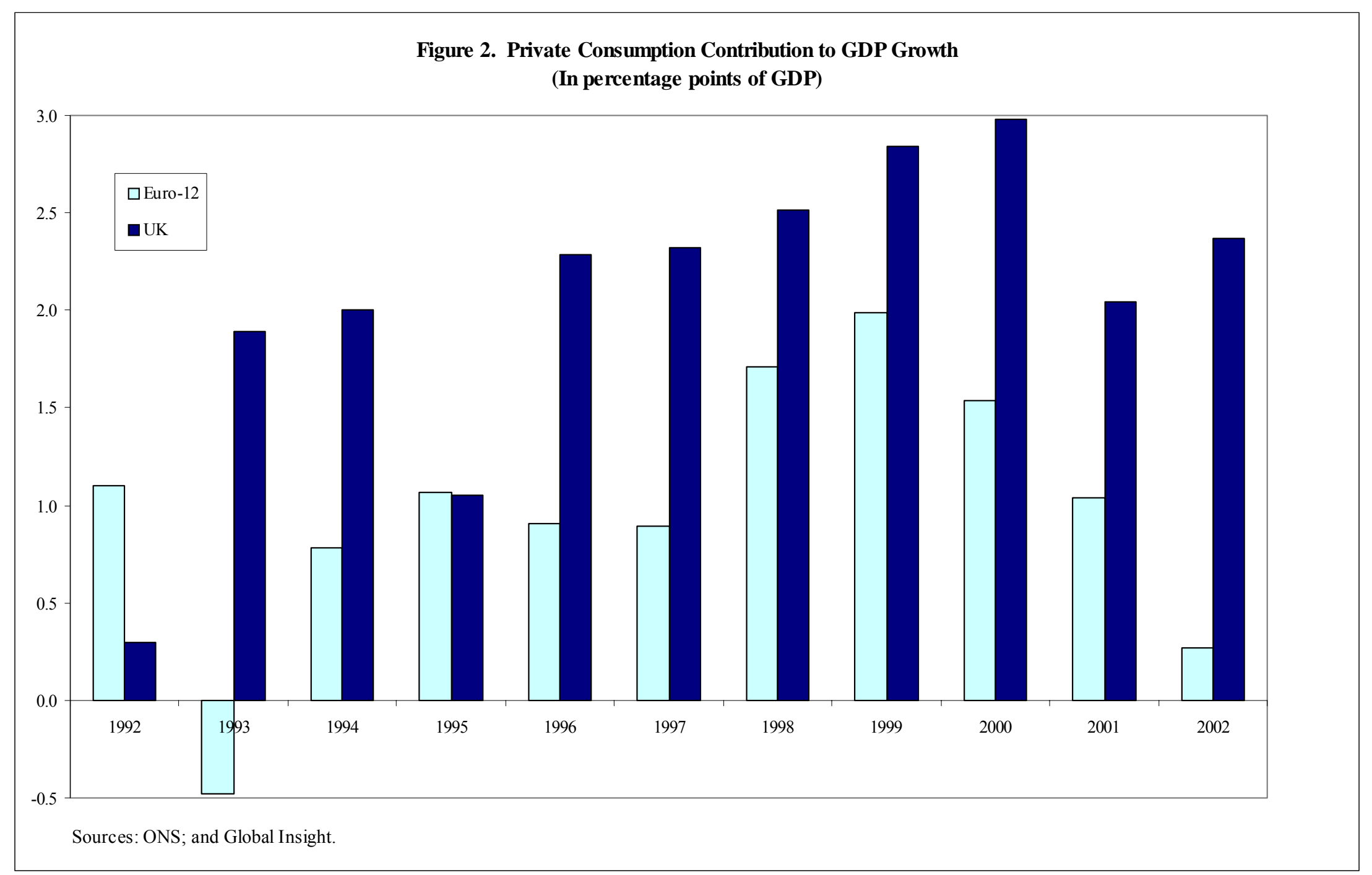




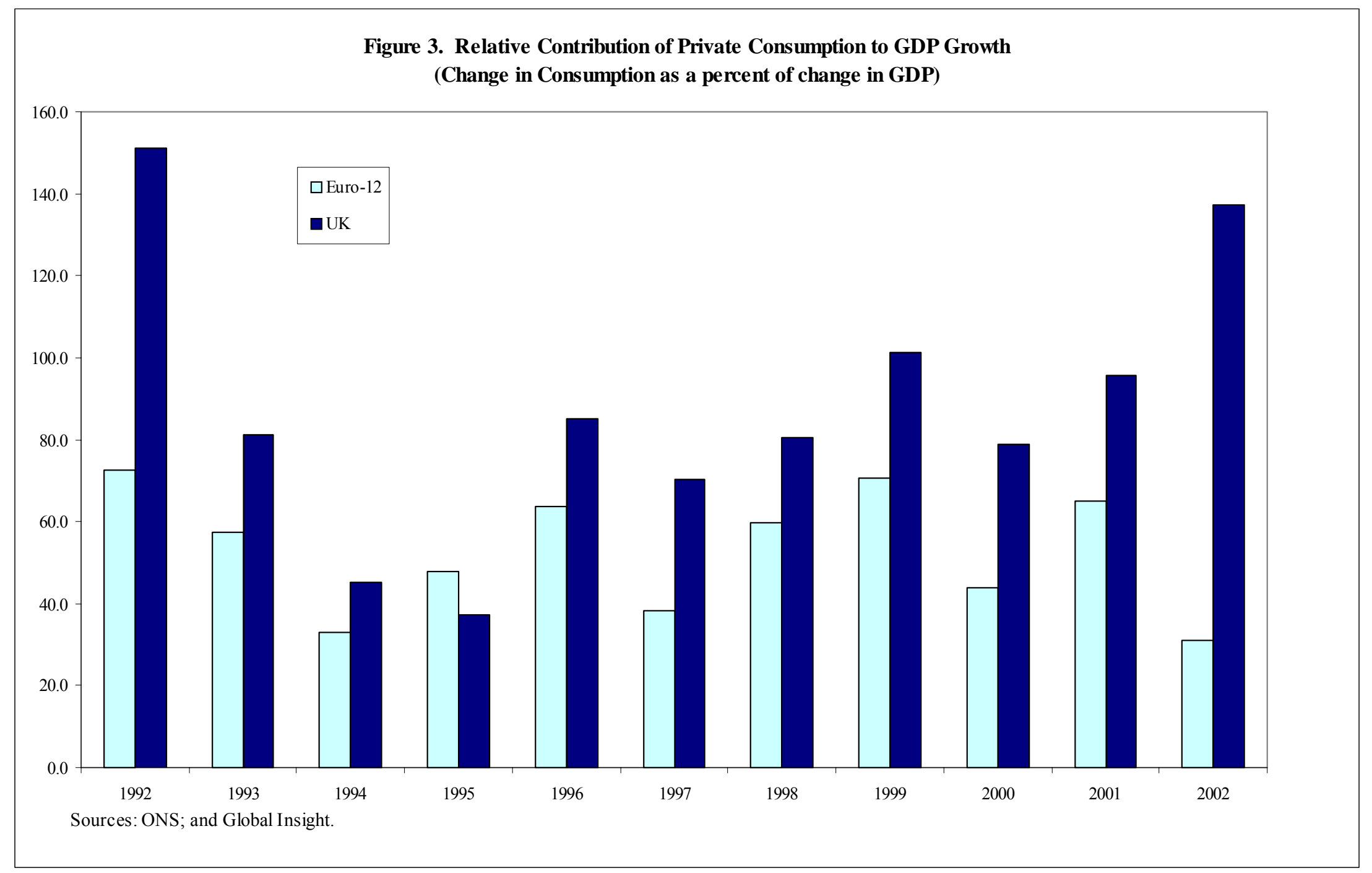




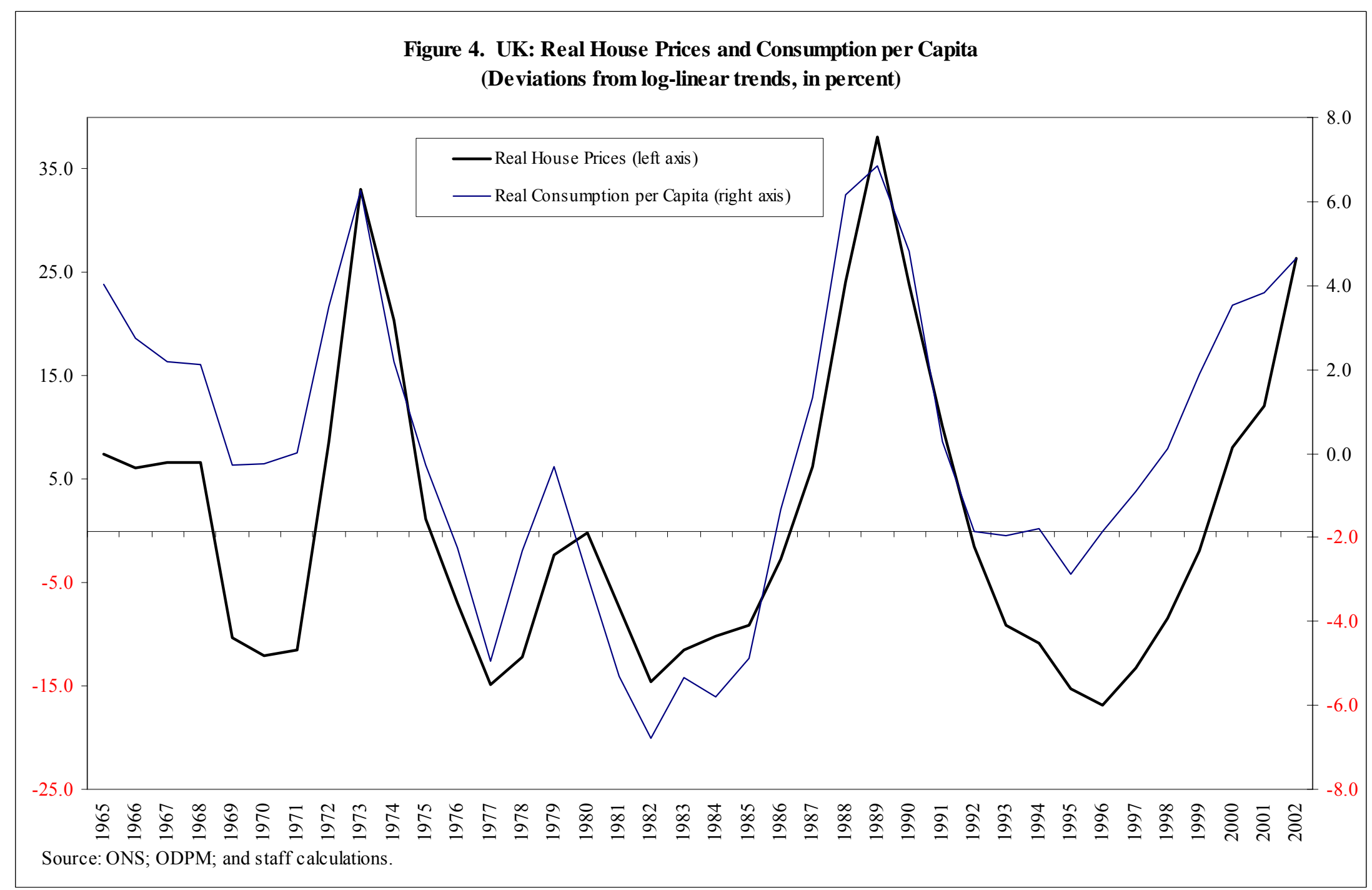


Figure 5. Correlation Coefficients between Private Consumption Growth and House Price Inflation, 1971-2001

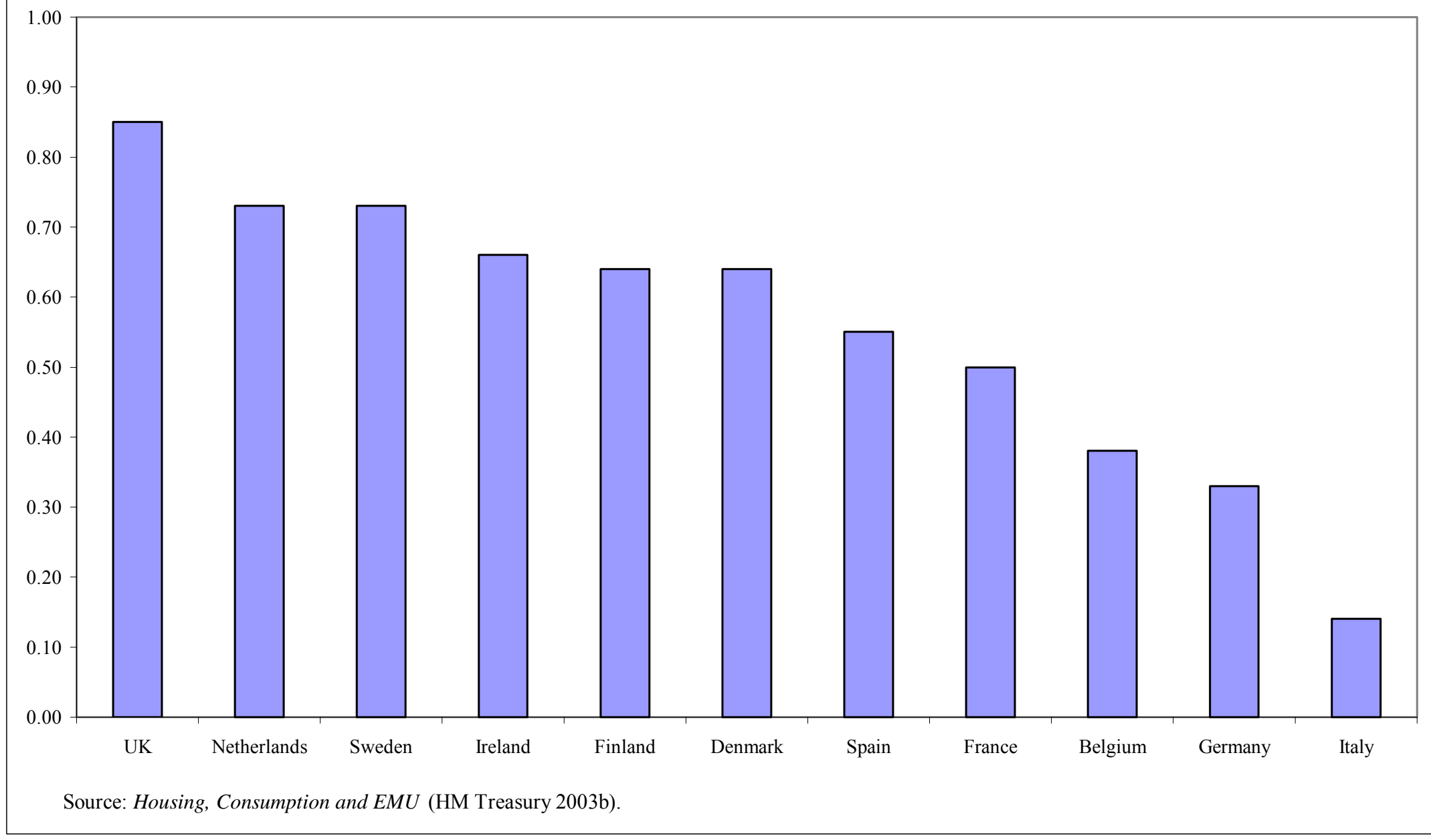




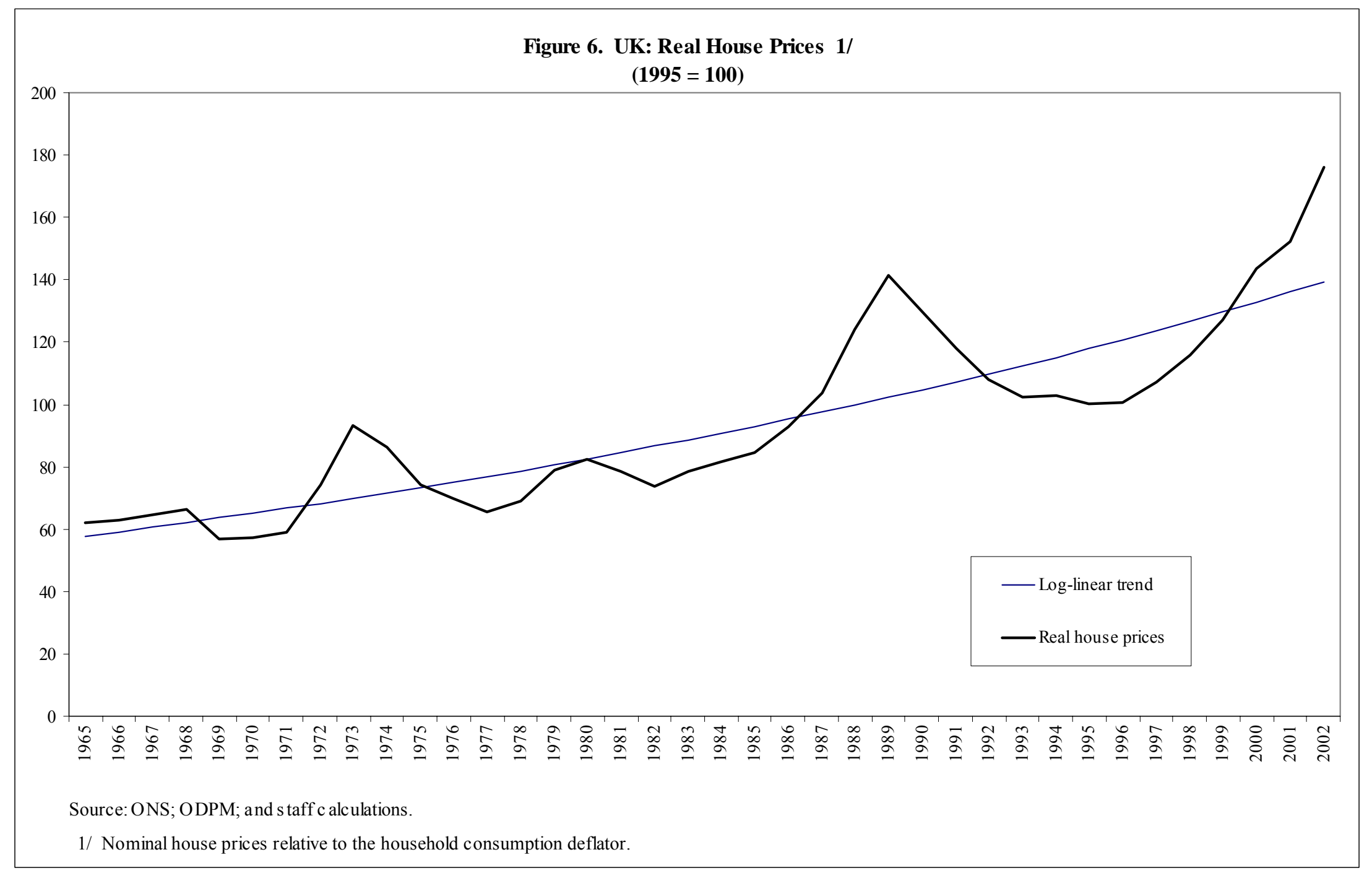




\section{APPENDIXES}

\section{The Option VAlue OF Delaying EMU EnTry}

This appendix illustrates the impact of uncertainty and irreversibility ${ }^{39}$ on the decision to enter EMU using a standard investment model, originally developed by McDonald and Siegel (1986) and extensively discussed in Dixit and Pindyck (1994).

The main result of the model is that in the presence of uncertainty and irreversibility, a simple net present value rule is no longer a correct guide to the decision to join EMU. This happens because entering now involves giving up the benefit of additional information that may become available later. Given this cost, it may be optimal not to enter now even if the net present value is positive. The optimal decision rule implies a "reluctance to enter," which depends on the amount of uncertainty about the value of joining EMU (the shape of the "return curve" in terms of the approach followed in the main text) - the more uncertain the value, the higher the reluctance to enter.

\section{Definitions}

Let the key variables in the model be defined as follows:

$V_{t}=$ value of joining EMU at time $t$;

$I=$ sunk cost of entry; ${ }^{40}$

$\rho=$ discount rate;

$T=$ unknown time of entry.

\section{Assumptions}

The two main assumptions of the model are formalized as follows:

${ }^{39}$ An investment project is partially or completely irreversible if its initial cost is at least partially sunk, i.e., "you cannot recover it all should you change your mind" (Dixit and Pindyck (p. 3, 1994)).

40 The existence of a "sunk cost"- - something that needs to be sustained by member countries at the moment of entry and cannot be recovered in case of exit - is introduced in the model to mimic the irreversibility of the entry decision. The higher the sunk cost, the more "irreversible" is the decision. Actual sunk costs in the case of EMU-entry are low (e.g., the cost of the change-over), unless one also includes those that may arise from entering when cyclical conditions are not appropriate. 
Assumption 1. The current value of joining EMU $\left(V_{t}\right)$ is uncertain. It follows a stochastic process described by a geometric Brownian motion with a drift parameter $\alpha$ and variance $\sigma^{2} t$ :

$$
d V=\alpha V d t+\sigma V d z
$$

where $d z$ is the increment of a Wiener process.

Assumption 2. The decision of EMU entry is irreversible, i.e. it involves incurring a sunk cost $I$.

\section{Optimization problem}

The objective is to find a decision rule that maximizes the expected value of joining EMU, given Assumptions 1 and 2:

$$
F(V)=\max E\left\{\left(V_{T}-I\right) e^{-\rho T}\right\}
$$

where $F(V)$ is the value of the opportunity to join EMU.

Using dynamic programming, the first-order condition (Belman equation) is: ${ }^{41}$

$$
\rho F d t=E(d F)
$$

Given the assumptions of the model and Ito's lemma, the Belman equation can be simplified to a second-order differential equation:

$$
\rho F(V)=\alpha V F^{\prime}(V)+\frac{1}{2} \sigma^{2} V^{2} F^{\prime \prime}(V)
$$

Also, the following boundary conditions need to be satisfied:

$$
\begin{gathered}
F(0)=0 \\
F\left(V^{*}\right)=V^{*} \\
F^{\prime}\left(V^{*}\right)=1
\end{gathered}
$$

\footnotetext{
${ }^{41}$ See Part II of Dixit and Pindyck (1994) for detailed discussion of the mathematical tools used in this annex.
} 


\section{Solution}

The solution to the above optimization problem is a decision rule, i.e. a critical value $V^{*}$ such that it is optimal to enter if and only if $V \geq V^{*}$. In this case, the critical value is given by:

$$
V^{*}=\frac{\lambda_{1}}{\lambda_{1}-1} I=\mu I
$$

where $\lambda_{1}$ is a root of Equation (4), i.e. $\lambda_{1}=\frac{1}{2}-\frac{\alpha}{\sigma^{2}}+\sqrt{\left(\frac{\alpha}{\sigma^{2}}-\frac{1}{2}\right)^{2}+\frac{2 \rho}{\sigma^{2}}}>1$.

In addition, the following relationship holds:

$$
\frac{\partial \mu}{\partial \sigma}>0
$$

\section{Interpretation}

It is interesting to note how uncertainty and irreversibility affect the decision rule for EMU entry. In the absence of these two factors, the critical value $V^{*}$ is identical to the sunk cost $I$. However, the presence of uncertainty and irreversibility creates a wedge $\mu$ between the critical value $V^{*}$ and $I$. Moreover, the size of the wedge increases as the uncertainty parameter $\sigma^{2}$ goes up (see Equations 6 and 7). The greater the uncertainty about the value of joining EMU (arising, for example, from uncertainty about the magnitude of the potential trade gains in a currency union), the higher the option of waiting to make the (irreversible) decision to enter. 


\section{DOMESTIC AND FOREIGN DIRECT INVESTMENT (FDI)}

The Assessment considers that, given sufficient stability, EMU entry would be beneficial for investment in the United Kingdom, both because of increased return prospects and because of a lower cost of capital. Rising trade and incomes, economies of scale, enhanced competition, and price transparency, all suggest the potential for higher returns from investment within EMU. The Assessment also argues that the businesses' cost of capital is likely to decline within EMU as a result of deeper and more liquid markets, particularly for small and medium enterprises for whom transaction costs and exchange rate volatility are more likely to represent significant barriers in seeking foreign finance. In contrast with the early studies on EMU membership, it is not expected that membership of EMU would result in lower underlying long-term interest rates. This is because medium- and long-term inflation and inflation risk premia have converged to euro-area levels over the late 1990s and capital mobility can be expected to align real rates. Indeed, the differentials with the euro area on long-term government bond yields and forward interest rates implied by the government yield curve have remained generally close to nil since the introduction of the euro (Figure A1).

The effect of EMU entry on FDI is probably positive. Recent studies tend to find a negative effect of the volatility of the effective exchange rate on FDI flows-a particular case of the negative effect that macroeconomic volatility has on investment. ${ }^{42}$ In this light, U.K. membership of EMU would increase FDI, as it is likely to make the effective exchange rate more stable despite a possible increase in volatility with respect to the U.S. dollar. ${ }^{43}$ However, it is possible that the latter impinges on FDI from the United States, which is a crucial source of FDI to the United Kingdom (Table 3), through the exposure of the investor to exchange rate risk relative to the country where the investment is located. Nevertheless, Barr et al. (2003), based on an analysis of stock returns, argue that this channel is unlikely to hinder FDI. In fact, FDI to the United Kingdom could expand after euro adoption if the purpose of the investment were to employ the United Kingdom as a platform to supply euroarea markets - since it would allow foreign investors in the United Kingdom to partly hedge their exposure by denominating their costs in the currency of their revenues. ${ }^{44}$

\footnotetext{
${ }^{42}$ See Byrne and Davis (2002 and 2003). Pain (2002) offers a more skeptical view on the importance of exchange rate volatility on FDI.

${ }^{43}$ This is analyzed in the background study The Exchange Rate and Macroeconomic Adjustment (HM Treasury 2003b). EMU entry, while eliminating the volatility with respect to the euro, might increase the volatility with respect to the U.S. dollar.

${ }^{44}$ See Barrel et al. (2003) and Becker and Hall (2003).
} 


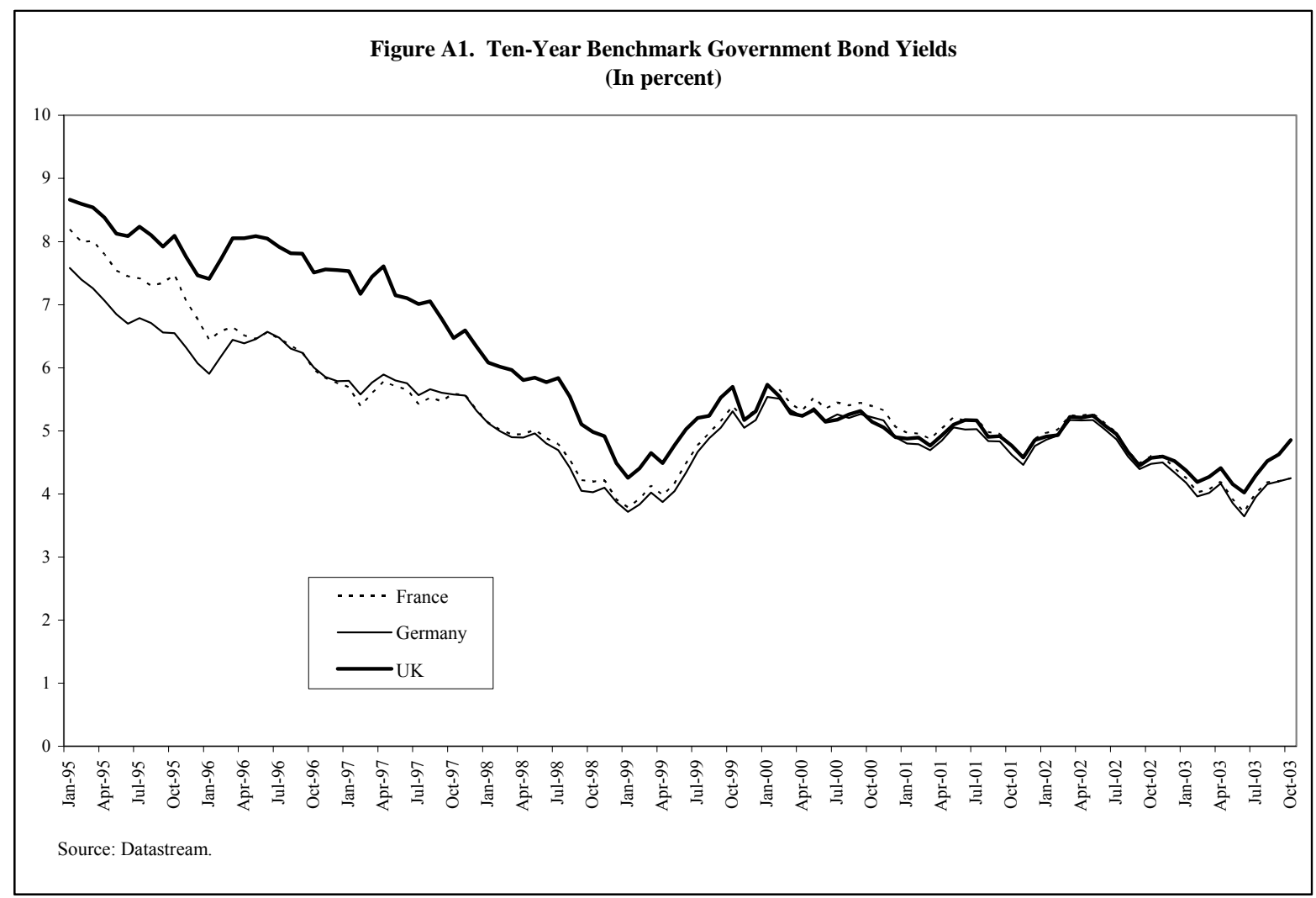

Table A1. United Kingdom: Inward FDI Flows by Origin

\begin{tabular}{|c|c|c|c|c|c|c|}
\hline & 1997 & 1998 & 1999 & 2000 & 2001 & Average \\
\hline & \multicolumn{6}{|c|}{ (In percent of GDP) } \\
\hline World total & 2.5 & 5.2 & 6.0 & 8.3 & 4.2 & 5.2 \\
\hline EU & 0.9 & 1.5 & 4.4 & 5.5 & 3.1 & 3.1 \\
\hline EMU-12 countries & 0.8 & 1.5 & 4.2 & 5.4 & 3.1 & 3.0 \\
\hline Other & 0.0 & 0.0 & 0.1 & 0.1 & 0.0 & 0.1 \\
\hline EFTA & 0.2 & 1.1 & -0.1 & 0.1 & -0.1 & 0.2 \\
\hline US & 1.2 & 2.2 & 1.8 & 1.3 & 0.9 & 1.5 \\
\hline \multirow[t]{2}{*}{ Other } & 0.2 & 0.4 & -0.1 & 1.3 & 0.3 & 0.5 \\
\hline & \multicolumn{6}{|c|}{ (In percent of world total) } \\
\hline World total & 100.0 & 100.0 & 100.0 & 100.0 & 100.0 & 100.0 \\
\hline $\mathrm{EU}$ & 34.0 & 28.2 & 73.0 & 66.7 & 73.3 & 55.0 \\
\hline EMU-12 ountries c & 32.2 & 28.0 & 70.5 & 65.3 & 72.3 & 53.7 \\
\hline Other & 1.8 & 0.2 & 2.4 & 1.4 & 1.0 & 1.4 \\
\hline EFTA & 7.4 & 22.0 & -1.2 & 0.9 & -3.0 & 5.2 \\
\hline US & 49.5 & 41.4 & 29.3 & 16.2 & 21.9 & 31.7 \\
\hline Other & 9.0 & 8.4 & -1.1 & 16.1 & 7.8 & 8.0 \\
\hline
\end{tabular}

Source: ONS. 
In practice, the early evidence on FDI flows, although still inconclusive, points to a possible reduction of the United Kingdom's share of inward FDI flows since the introduction of the euro. Table 4 shows the share of FDI inflows into the EU countries that stayed out of the euro as a proportion of total inflows into EU countries (including from other EU countries). These shares appear to have declined overall since the introduction of the euro. These data, however, should be taken with caution as FDI flows show high volatility over time and the figures for the late 1990s and 2000 are greatly affected by the mergers and acquisitions wave. Table 5 shows that the United Kingdom has also received a lower share of the non-EU FDI into the EU since the creation of the euro in 1999, while the euro area has clearly increased its share. A possible explanation, unrelated to EMU, would be the decline since 2000 in U.S. outward FDI flows, which tend to favor the United Kingdom. This may have played a role, but nevertheless the last columns in Table 5 indicate that the United Kingdom has also received a smaller share of U.S. FDI flows to the EU since the launch of the euro. Availability of consistent cross-country data, however, is still severely limited and the evidence, although suggestive, does not allow for statistically significant inferences.

In conclusion, the results from existing research and empirical evidence on the effect of EMU entry on investment are mixed but, on balance, point to a positive effect - or equivalently, to a negative effect of remaining outside the euro. The effect on FDI is of particular importance, since FDI has played a key role in increasing productivity and TFP in the United Kingdom - including through inter- and intra-industry spillovers - a central objective of government policies. ${ }^{45}$ The evidence on actual FDI flows since the introduction of the euro appears to show a positive effect of EMU membership — although this should be taken with caution since FDI is notoriously erratic and the data base is still limited.

Table A2. FDI Inflows into EU "Out" Countries

(In percent of total FDI inflows into EU countries)

\begin{tabular}{|c|c|c|c|c|c|c|c|c|}
\hline & 1970 & 1975 & 1980 & 1985 & 1990 & 1995 & 2000 & 2001 \\
\hline UK & 29.0 & 33.6 & 47.5 & 34.5 & 33.8 & 17.4 & 14.4 & 16.7 \\
\hline Sweden & 2.0 & 2.7 & 0.2 & 0.8 & 1.3 & 3.6 & 4.0 & 2.2 \\
\hline Denmark & 2.1 & 0.8 & 1.2 & 2.7 & 2.2 & 12.6 & 2.9 & 3.9 \\
\hline Total above & 33.1 & 37.1 & 48.9 & 38.0 & 37.3 & 33.6 & 21.3 & 22.8 \\
\hline
\end{tabular}

Source: Barr et al. (2003) from UNCTAD.

${ }^{45}$ See Griffith, Redding, and Simpson (2002); and Hubert and Pain (2000). 
Table A3. FDI Inflows from Outside the EU

(In percent of total inflows into the EU from outside, except when indicated)

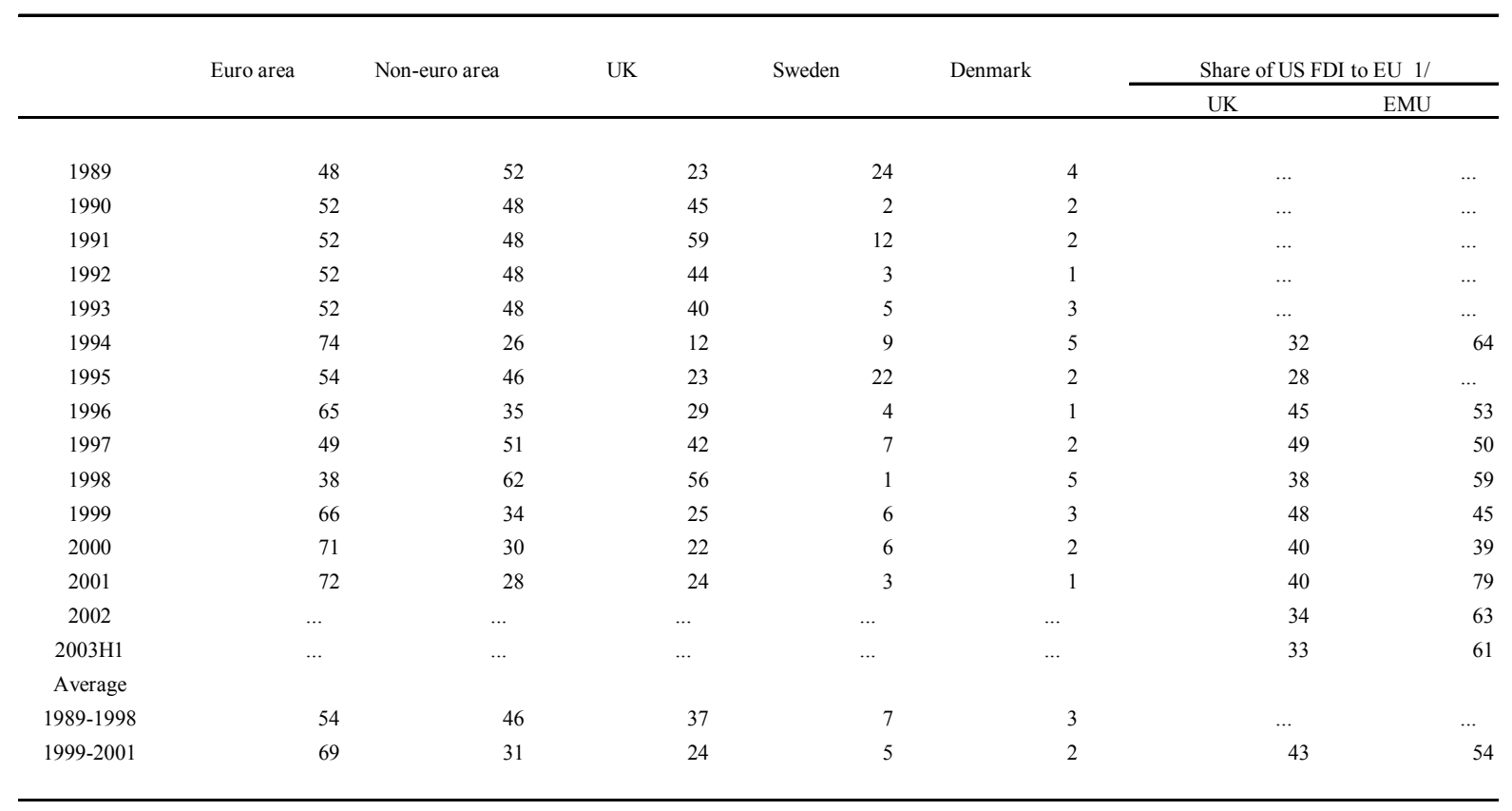

Source: Barr et al. (2003); and U.S. Bureau of Economic Analysis.

1/ Net outflows to the indicated jurisdiction as a percent of net U.S. FDI outflows to the EU. 


\section{References}

Anderson, M. A., and S.S. Smith, 1999, "Do National Borders Really Matter? Canada-U.S. Regional Trade Reconsidered," Review of International Economics, Vol. 7, No. 2.

Barr, D., F. Breedon, and D. Miles, 2003, "Life on the Outside: Economic Conditions and Prospects Outside Euroland," Economic Policy, October.

Barrell, R., 2002, "The UK and EMU: Choosing the Regime," National Institute Economic Review No. 180.

- S.D. Gottschalk, and S.G. Hall, 2003, "Foreign Direct Investment and Exchange Rate Uncertainty in Imperfectly Competitive Industries,” NIESR Discussion Paper 220.

Becker, B., and S.G. Hall, 2003, "Foreign Direct Investment in Industrial R\&D and Exchange Rate Uncertainty in the UK," NIESR Discussion Paper 217.

Begg, D., O. Blanchard, D. Coyle, B. Eichengreen, J. Frankel, F. Giavazzi, R. Portes, P. Seabright, L. A. Winters, A. Venables, and C. Wyplosz, 2003, "The Consequences of Saying No: An Independent Report into the Economic Consequences of the UK Saying No to the Euro," report published by Britain in Europe.

Bun, M.J.G., and F.J.G.M. Klaassen, 2002, "Has the Euro Increased Trade?” Timbergen Institute Discussion Paper TI 2002-108/2.

— 2003, "The Importance of Accounting for Time Trends When Estimating the Euro Effect on Trade," unpublished (October 17, 2003).

Byrne, J.P., and E.P. Davis, 2002, "Investment and Uncertainty in the G7," NIESR Discussion Paper 198.

— 2003, "Panel Estimation of the Impact of Exchange Rate Uncertainty on Investment in the Major Industrial Countries," NIESR Discussion Paper 208.

Chancellor Brown, Gordon, 1997, "Statement on EMU," 17 October 1997 Speech in the House of Commons (http://www.hm-treasury.gov.uk).

Dixit, A. K., and R. S. Pindyck, 1994, "Investment Under Uncertainty," Princeton University Press, Princeton, New Jersey.

Dubel, A., S. Low, and M. Sebag-Montefiore, 2003, "Study on the Financial Integration of European Mortgage Markets," Mercer Oliver Wyman and European Mortgage Federation, Brussels (http://www.hypo.org).

European Central Bank, 2002, "Structural Factors in the EU Housing Markets," March (http://www.ecb.int). 
European Commission, DG Economic and Financial Affairs, 1990, "One Market, One Money: An Evaluation of the Potential Benefits and Costs of Forming an Economic and Monetary Union," European Economy 44.

Frankel, J.A., and D. Romer, 1999, "Does Trade Cause Growth?” American Economic Review Vol. 89 No. 3.

Frankel, J.A., and A.K. Rose, 2000, "Estimating the Effect of Currency Unions on Trade and Output,” NBER Working Paper No. 7857.

Griffith, R., S. Redding, and H. Simpson, 2002, "Productivity Convergence and Foreign Ownership at the Establishment Level,” Institute for Fiscal Studies (IFS) Working Paper W02/22.

Hardt, J., and Earley, F. 2003, "European Integration in the Mortgage Lending Industry: Developments Since the Euro," European Mortgage Federation, Brussels (http://www.hypo.org).

HM Treasury, 1997, "UK Membership of the Single Currency: An Assessment of the Five Economic Tests," HM Treasury, October 1997 (http://www.hm-treasury.gov.uk).

_ 2003a, "UK Membership of the Single Currency: An Assessment of the Five Economic Tests," HM Treasury, June 2003 (http://www.hm-treasury.gov.uk).

— , 2003b, "EMU Studies,” HM Treasury, June 2003 (http://www.hm-treasury.gov.uk).

Hubert, F., and N. Pain, 2000, "Inward Investment and Technical Progress in the UK Manufacturing Sector,” OECD Economics Department Working Paper No. 268.

International Monetary Fund (IMF), 2003, “An Analysis of House Prices in the United Kingdom,” in United Kingdom: Selected Issues, IMF Staff Country Report No. 03/47 (http://www.imf.org).

_ 2000, "Costs and Benefits of Joining the EMU," in United Kingdom: Selected Issues, IMF Staff Country Report No. 00/106 (http://www.imf.org).

Layard, R., 2002, “Britain Will Pay the Price of Exclusion,” Financial Times, October 15.

Lucas, R. E. Jr., 2003, “Macroeconomic Priorities,” American Economic Review, March.

Ludwig, A., and T.M. Slk, 2002, "The Impact of Changes in Stock Prices and House Prices on Consumption in OECD Countries," IMF Working Paper No. 02/1.

McCallum, J., 1995, "National Borders Matter: Canada-U.S. Regional Trade Patterns," American Economic Review, Vol. 85, No. 3. 
McDonald, R., and D. Siegel, 1986: "The Value of Waiting to Invest," Quarterly Journal of Economics, Vol. 101, No.4.

Micco, A., E. Stein, and G. Ordoñez, 2003, “The Currency Union Effect on Trade: Early Evidence from EMU," Economic Policy, October.

Mundell, R., 1961, "A Theory of Optimum Currency Areas," American Economic Review, Vol. 51, No. 4, pp. 657-65.

Pain, N., 2002, “EMU, Investment and Growth: Some Unresolved Issues,” National Institute Economic Review No. 180.

Ramey, G., and V. A. Ramey, 1995, "Cross-Country Evidence on the Link Between Volatility and Growth," American Economic Review, Vol. 85, No. 5., December.

Rose, A. K., 2000, "One Money, One Market: The Effect of Common Currencies on Trade," Economic Policy, April.

Swank, J., J. Kakesa and A. F. Tiemana, 2002, “The Housing Ladder, Taxation, and Borrowing Constraints," De Nederlandsche Bank, Monetary and Economic Policy Department, MEB Series Working Paper 2002-9 (http://www.dnb.nl/zoeken/index.htm)

Wren-Lewis, S., 2003, "Changing the Rules: Why We Should Not Accede to EMU's Current Fiscal Regime," New Economy, Vol. 10, No. 2. 